\title{
SARS-CoV-2 and Coronavirus Disease Mitigation: Treatment Options, Vaccinations and Variants
}

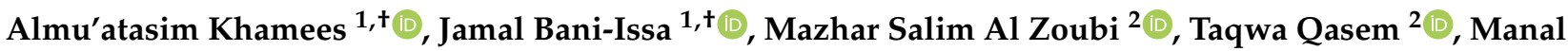

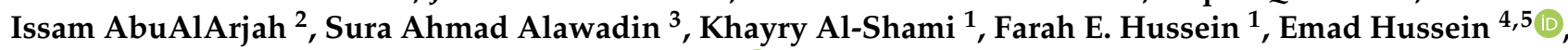 \\ Ibrahim H. Bashayreh ${ }^{6}$, Murtaza M. Tambuwala ${ }^{7}$ (D), Mohannad Al-Saghir ${ }^{8}$ and Christopher T. Cornelison ${ }^{9, *(D)}$
}

Citation: Khamees, A.; Bani-Issa, J.; Zoubi, M.S.A.; Qasem, T.;

AbuAlArjah, M.I.; Alawadin, S.A.; Al-Shami, K.; Hussein, F.E.; Hussein, E.; Bashayreh, I.H.; et al. SARS-CoV-2 and Coronavirus Disease Mitigation: Treatment Options, Vaccinations and Variants. Pathogens 2022, 11, 275. https://doi.org/10.3390/ pathogens 11020275

Academic Editor:

Danièlle Gunn-Moore

Received: 14 January 2022

Accepted: 10 February 2022

Published: 20 February 2022

Publisher's Note: MDPI stays neutral with regard to jurisdictional claims in published maps and institutional affiliations.

Copyright: (C) 2022 by the authors. Licensee MDPI, Basel, Switzerland. This article is an open access article distributed under the terms and conditions of the Creative Commons Attribution (CC BY) license (https:// creativecommons.org/licenses/by/ $4.0 /)$.
1 Department of Clinical Sciences, Faculty of Medicine, Yarmouk University, Irbid 211-63, Jordan; almotasem.kh@gmail.com (A.K.); jamal.bani.issa.md@gmail.com (J.B.-I.); khyree20000@gmail.com (K.A.-S.); 2021999358@ses.yu.edu.jo (F.E.H.)

2 Department of Basic Medical Sciences, Faculty of Medicine, Yarmouk University, Irbid 211-63, Jordan; mszoubi@yu.edu.jo (M.S.A.Z.); takwaqasem95@gmail.com (T.Q.); manalessam12@yahoo.com (M.I.A.)

3 Faculty of Pharmacy, Y armouk University, Irbid 211-63, Jordan; suraahmad95@gmail.com

4 Department of Food Science and Human Nutrition, A'Sharqiyah University, P.O. Box 42, Ibra 400, Oman; emad.hussein@asu.edu.om

5 Department of Biological Sciences, Faculty of Sciences, Yarmouk University, Irbid 211-63, Jordan

6 Nursing Department, Fatima College of Health Sciences, Al-Ain Campus, P.O. Box 24162, Abu-Dhabi 31201, United Arab Emirates; ibrahim.bashayreh@fchs.ac.ae

7 School of Pharmacy and Pharmaceutical Science, Ulster University, Coleraine BT52 1SA, UK; m.tambuwala@ulster.ac.uk

8 Department of Biological Sciences, Ohio University, Zanesville, OH 43701, USA; al-saghi@ohio.edu

9 Department of Molecular and Cellular Biology, Kennesaw State University, Kennesaw, GA 30144, USA

* Correspondence: ccornel5@kennesaw.edu

+ Both authors contributed equally to this manuscript.

\begin{abstract}
COVID-19 is caused by a novel coronavirus (2019-nCoV), which was declared as a pandemic after it emerged in China 2019. A vast international effort has been conducted to prevent and treat COVID-19 due to its high transmissibility and severe morbidity and mortality rates, particularly in individuals with chronic co-morbidities. In addition, polymorphic variants increased the need for proper vaccination to overcome the infectivity of new variants that are emerging across the globe. Many treatment options have been proposed and more than 25 vaccines are in various stages of development; however, the infection peaks are oscillating periodically, which raises a significant question about the effectiveness of the prevention measures and the persistence of this pandemic disease. In this review, we are exploring the most recent knowledge and advances in the treatment and vaccination options as well as the new emerging variants of 2019-nCoV and the possible mitigation of one of the most aggressive pandemics in the last centuries.
\end{abstract}

Keywords: 2019-nCoV; COVID-19; vaccines; variants; pandemic

\section{Introduction}

Novel coronavirus (2019-nCoV) or the severe acute respiratory syndrome coronavirus 2 (SARS-CoV-2) causes a disease known as coronavirus disease 2019 (COVID-19). SARSCoV-2 belongs to the Coronaviridae family, a group of associated viruses with a singlestranded RNA that may cause respiratory infection with mild to lethal symptoms [1,2]. It was first recognized in Wuhan City, Central China, in December 2019, then spread quickly over the world, resulting in millions of deaths with an $11 \%$ mortality rate [3-5]. Coronavirus is an enveloped and non-segmented virus that has small crown-shaped spikes projecting from its surface with a size between (80-160 NM) [6]. The World Health Organization (WHO) considered SARS-CoV-2 as one of the most highly pathogenic $\beta$-coronaviruses infecting humans. Therefore, early diagnosis of COVID-19 is the most crucial step in 
treating the infection. Molecular methods were the most generally used tool in diagnosis, such as PCR [7]. After diagnosis, suspected and confirmed cases should be immediately treated in specially designated and supported hospitals with professional isolation and safe conditions [5]. Control of acute hypoxic respiratory failure in COVID-19 patients is the first step in treatment. Many trials were conducted to find an effective and safe therapeutic candidate. For instance: dexamethasone therapy was effective in reducing the mortality rate in patients requiring oxygen supplements [8,9]. This review summarizes the most effective drugs that have been used and evaluated for COVID-19 treatment during the pandemic and current knowledge about available vaccines and vaccine candidates.

\section{The Pathogenic Mechanisms That Lead to Severe Lung Disease}

Although more than two years have passed since the COVID-19 pandemic, the mechanism of the disease and its spread are still unclear [10]. In general, the mechanism of the disease can be divided into three stages:

The first stage, which can be referred to as an asymptomatic state:

The SARS-COV-2 virus is linked to the epithelial cells in the nasal cavity, where it begins to multiply. At this stage, the patient has no symptoms, and the presence of the virus can be confirmed by nasal swabs. This stage is characterized by the fact that even if the patient does not show symptoms, they are capable of transmitting the virus. The RT-PCR value can be used to predict viral load and subsequent infection [10].

The second stage:

The virus travels through the airways and an innate immune response occurs. At this stage, the presence of the virus can be confirmed through nasal or sputum samples, as well as by signs of the innate immune response and clinical symptoms. The level of CXCL10, which is an interferon-responsive gene, is used as a predictor of the clinical course and an indication of the noise-ratio of type II squamous cell responses to respiratory infections such as MERS-CoV and influenza [11,12].

The third stage:

Only $20 \%$ of the infected people reach this stage when they develop a pulmonary infiltration. It is estimated that the mortality rate is $2 \%$, and varies according to the age of the infected person. At this stage, the virus reaches the gas exchange units inside the lungs, where it infects the second type of warm cells, where the virus is concentrated inside this type of cells and uses them as an amplification site, as these cells die when the virus is released. In this way, the lung will experience a significant loss of type II cells, which leads to the activation of a secondary healing pathway. Consequently, this leads to abnormal healing that results in scars and fibrosis inside the lungs. Older adults are most susceptible and most affected by this stage due to a weak immune response and a low rate of epithelium repair $[10,12,13]$. Moreover, Muratori et al. studied the effect of the presence of antinuclear antibodies in patients with moderate to severe COVID-19. They found that patients with antinuclear antibodies (positive-ANA) had a significantly worse COVID-19 prognosis than those who did not have these antibodies (negative-ANA) [13].

\section{Treatments}

\subsection{Usual Care and Respiratory Support}

The National Institutes of Health (NIH) provided guidelines for the supportive management of acute hypoxic respiratory failure caused by COVID-19 [14-16]. Approximately 75\% of COVID-19 hospitalized patients required oxygen supply therapy. On the other hand, for patients who require invasive mechanical ventilation, a lung-protective ventilation approach with low tidal volumes around $(4-8 \mathrm{~mL} / \mathrm{kg})$ and plateau pressure lower than $30 \mathrm{~cm} \mathrm{H} \mathrm{H}_{2} \mathrm{O}$ is strongly recommended with an application of positive end-expiratory pressure (PEEP) in moderate to severe cases [15]. The relationship between COVID-19 and respiratory failure is still being resolved. Many patients had normal breathing parameters but were severely hypoxemic [17]. 


\subsection{Pharmaceutical Drugs for COVID-19}

Since the emergence of the 2019-nCoV pandemic, and due to its rapid spread, it was of utmost importance to resolve viral virulence and develop effective therapeutics. Primary treatment started in China by using intravenous and oral antibiotics as the $\mathrm{CoV}$ appeared during the influenza season $[18,19]$. To date, no reliable evidence of an effective drug against 2019-nCoV has emerged [20]. Many therapeutics were used to treat previous coronaviruses, including SARS and MERS, such as ribavirin, nitazoxanide, penciclovir, nafamostat, chloroquine, corticosteroid, as well as the most common antiviral agents like Remdesivir and favipiravir. Only two of these therapeutics (chloroquine and Remdesivir) were validated with high efficiency in treating SARS-CoV-2 infection, ex vivo [7,21].

\subsubsection{Chloroquine}

Several studies demonstrated the positive impact of the sulfate and phosphate salts of chloroquine, a broadly used antimalarial and autoimmune disease therapeutic in the treatment of patients with COVID-19 [22,23]. The antiviral activity of chloroquine was first demonstrated in vitro in the 1960s with several types of viruses [24-26]. It has been evaluated in many chronic viral diseases. For example, chloroquine was utilized in the treatment of HIV patients but was ultimately ineffective [27]. In clinical viral therapy, chloroquine was only effective against chronic hepatitis $\mathrm{C}$ [28]. Chloroquine demonstrated its inhibitory impacts against COVID-19 by enhancing the endosomal $\mathrm{pH}$ required for the fusion of viral cells. Additionally, it induced the glycosylation of cellular receptors of SARS-CoV-2 (Figure 1) [29]. Approximately 200 trials of chloroquine/hydroxychloroquine suppressed in vitro entry and endocytosis of the virus [30,31]. Wang et al. concluded that "chloroquine was highly effective for in vitro control of CoV-19 infection and it should be tested in human patients suffering from the novel coronavirus disease" [31].

Despite these aforementioned promising results, several large randomized clinical trials found no benefit to mortality or other clinical aspects in hospitalized COVID-19 patients treated with chloroquine/hydroxychloroquine [32-36]. One such study randomized 150 patients, of which two had severe disease, and 148 had mild to moderate disease, to either standard of care alone, or standard of care plus hydroxychloroquine, and did not find a significantly higher probability of negative conversion due to hydroxychloroquine and reported that adverse events were higher in hydroxychloroquine recipients than in non-recipients [33]. Furthermore, in June 2020, the United States Food And Drug Administration (FDA) revoked its emergency use authorization (EUA) for these agents in patients with severe COVID-19, noting that the known and potential benefits no longer outweighed the known and potential risks [37].

\subsubsection{Remdesivir}

Remdesivir is an antiviral prodrug and has activity against a broad spectrum of viruses, for instance, Nipah virus, Ebola virus, middle east respiratory syndrome (MERS)-CoV, and severe acute respiratory syndrome (SARS)-CoV $[38,39]$. Since the 2019-nCov had a positive sense RNA and depended on RNA-dependent RNA RdRP polymerases for replication, drugs like Remdesivir were considered as candidate therapeutics for Coivd-19 treatment $[40,41]$. The active metabolite form of Remdesivir (GS-443902) is an adenosine analog that accumulates in cells and works as a viral RdRP inhibitor, and therefore inhibits viral RNA replication (Figure 2) [39,42]. 


\section{Chloroquine}

Potential mechanisms of action against coronaviruses

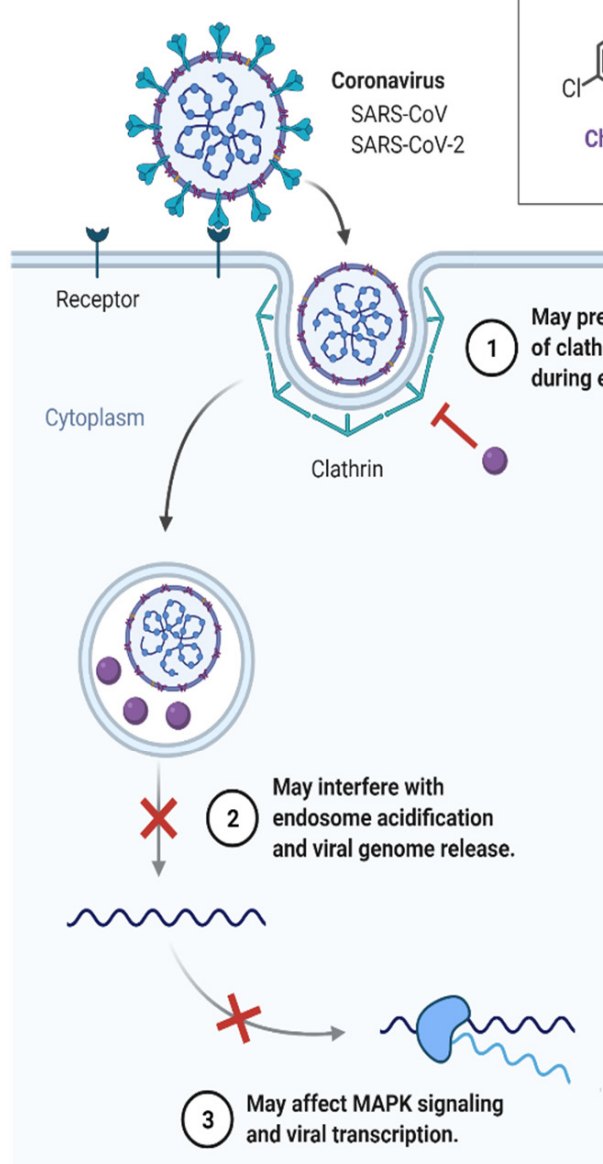<smiles>CCN(CC)CCCC(C)Nc1ccnc2cc(Cl)ccc12</smiles>

Chloroquine (CQ)<smiles>CCN(CCO)CCCC(C)Nc1cccc2cc(Cl)ccc12</smiles>

Hydroxychloroquine (HCQ)

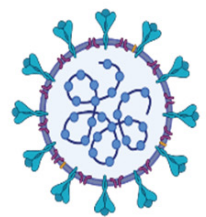

May interfere with vacuole formation and viral budding.

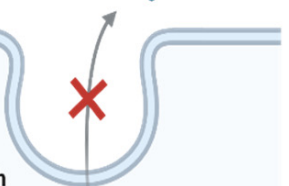

(4) May affect protein post-translational modification and viral assembly.
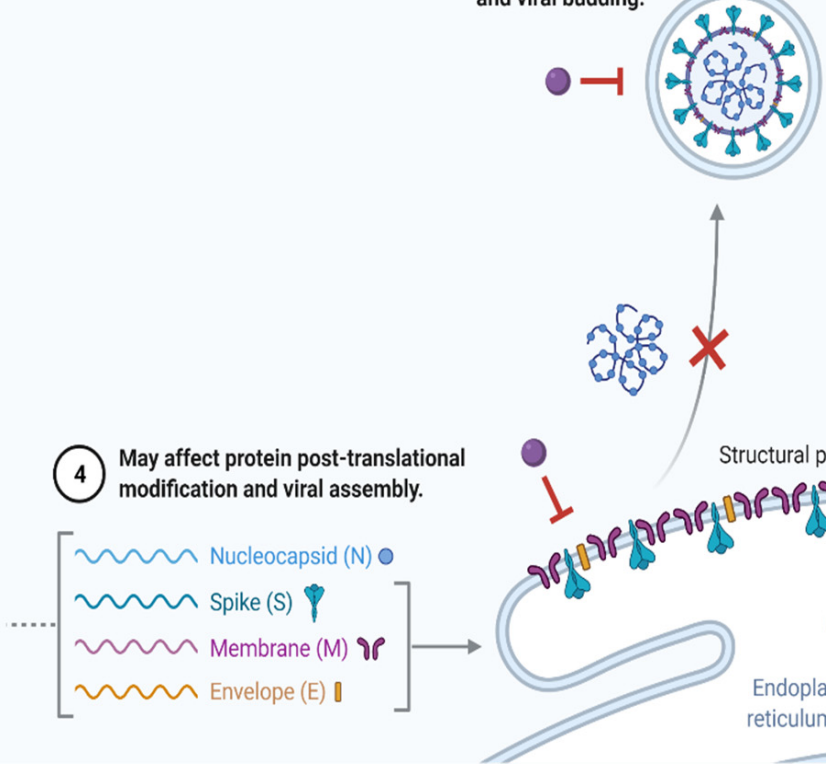

Endoplasmic reticulum (ER)

Figure 1. The mechanisms of action of chloroquine against coronaviruses. (Created with BioRender. com, accessed on 10 January 2022).

In vitro studies showed that Remdesivir had a potential efficacy against 2019$\mathrm{nCoV}[31,43]$. One such study demonstrated that Remdesivir inhibited the viral reproduction in E96-cells infected by 2019-nCov [43]. Pre-existence in vitro studies illustrated that Remdesivir inhibited viral reproduction in several types of cells infected by SARS-CoV and MERS-CoV [44,45]. Additionally, another study in the rhesus macaque model infected by MERS-CoV reported that Remdesivir reduced the viral loads in the lungs, trachea, bronchi, tonsils, and mediastinal lymph nodes [46]. Nevertheless, the results from the experiment in rhesus macaque infected by SARS-CoV-2 and treated by Remdesivir were novel and only gave a glimmer of hope. Even though the outcomes from in vivo and ex vivo experiments suggested that Remdesivir may be a suitable treatment for COVID-19, they did not reflect that Remdesivir reduced the mortality rate or improved recovery time in patients with COVID-19. In May 2020, the United States food and drug administration (FDA) issued emergency use authorization (EUA) for Remdesivir. Since that time, many studies have been initiated with COVID-19 patients to evaluate the safety and efficacy of Remdesivir [38]. 


\section{Remdesivir}

Potential repurposed drug candidate for COVID-19

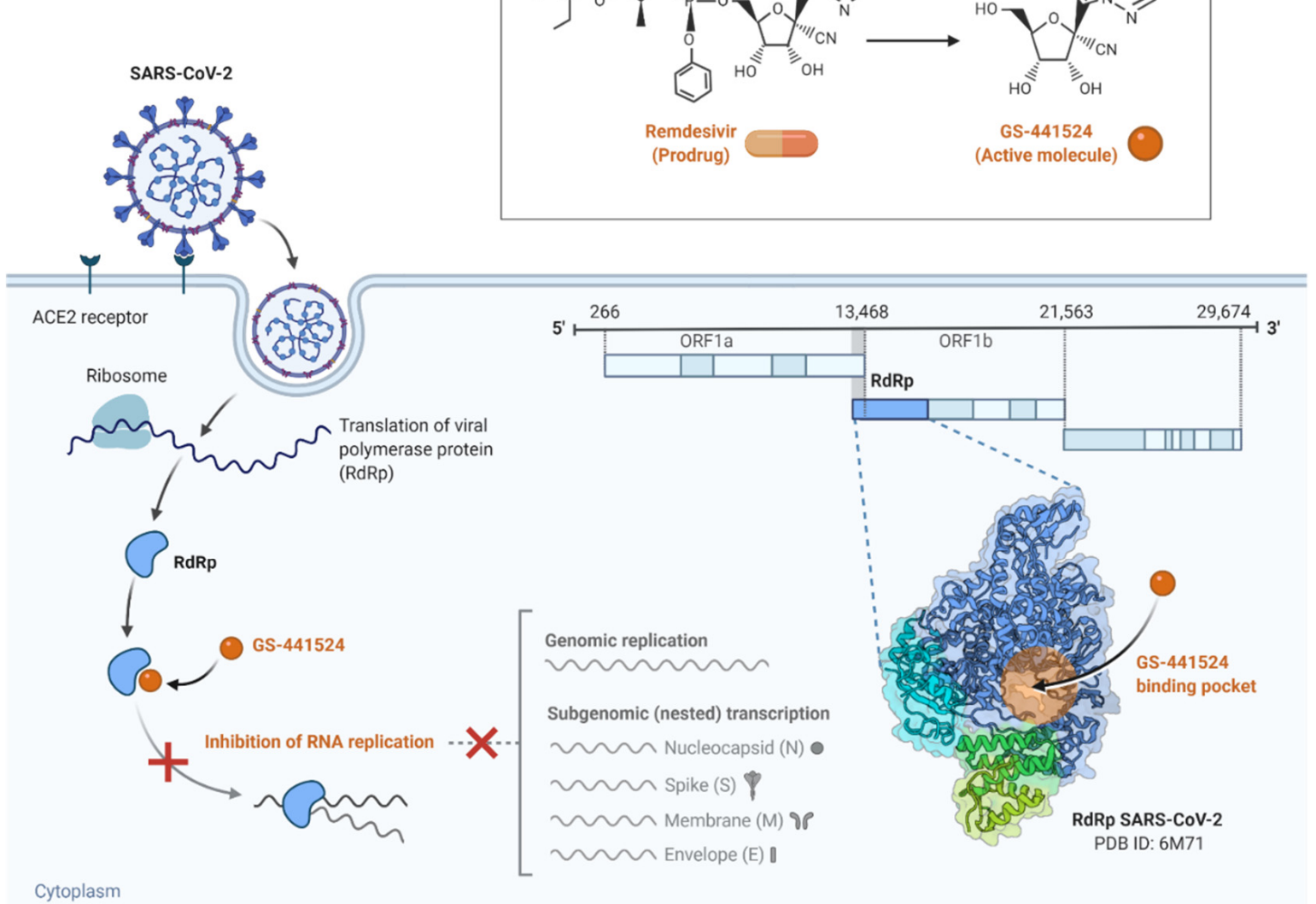

Figure 2. The mechanisms of action of Remdesivir against coronaviruses. (Created with BioRender. com, accessed on 10 January 2022).

Beigel and colleagues designed a placebo-controlled trial with 1062 patients (541 patients received Remdesivir while 521 received placebo) for up to 10 days. The median recovery time for patients who received Remdesivir was shorter in comparison to the placebo group (10 days versus 15 days, respectively). By day 15 , the mortality rate in the Remdesivir group and placebo group was $6.7 \%$ and 11.9 , respectively. Beigel and colleagues concluded that Remdesivir was superior to placebo in reducing recovery time in hospitalized patients with COIVD-19 [47].

The WHO solidarity trial is an open-label randomized trial conducted in 30 different countries and included 11,266 hospitalized patients with COIVD-19 to examine the efficacy and safety of four antiviral drugs that might be active in COVID-19 treatment. The WHO solidarity trial results showed that neither Remdesivir nor the other antiviral drugs included in the study had the potential impact on the clinical improvement of patients [48]. In a placebo-controlled trial of over ten hospitals in Hubei, China, 232 patients with 2019-nCoV infection had been recruited (158 received Remdesivir and 78 received placebo). The findings of this trial demonstrated that Remdesivir was not associated with a reduction in recovery time or mortality rate [49]. Additionally, in a randomized open-label trial with no placebo control, 397 patients were subdivided into two courses (200 patients for 5 days and 197 for 10 days) and illustrated that the difference between the two courses was not significant [42]. 
Spinner et al. designed an experiment with a standard care group as a control group where 584 patients were subdivided into three subgroups (193 patients for a 10-day course, 191 patients for a five-day course, and 200 patients in standard care group). On day 11, patients in the five-day course had better clinical improvement than the standard care group, but the difference between patients in the 10-day course and patients in the standard care group was not statistically significant [41]. Another meta-analysis showed a significant improvement in the recovery rate for patients admitted to the hospital with severe COVID 19 symptoms and treated by 10 days of Remdesivir. Those patients showed improvement in their symptoms on the seventh day with no significant difference in the patients' health condition on the twenty-eighth day. This indicates that Remdesivir is more useful at the beginning treatment plan [47].

\subsubsection{Baricitinib (As Adjunct to Remdesivir)}

Baricitinib, a reversible Janus-associated kinase (JAK) inhibitor, interrupts the signaling of multiple cytokines implicated in COVID-19 immunopathology. In addition to its immunomodulatory effects, it is thought to have potent antiviral effects through interference in viral entry [50]. In the United States, the FDA issued an emergency use authorization (EUA) for baricitinib to be used in combination with Remdesivir in patients with COVID-19 who require oxygen or ventilatory support while noting that there is limited information on its use in patients receiving systemic corticosteroids [51].In a randomized trial of 1033 hospitalized adults with COVID-19, the use of baricitinib in combination with Remdesivir reduced time to recovery (defined as a hospital discharge or continued hospitalization without the need for oxygen or medical care), when compared with placebo plus Remdesivir (7 versus 8 days, RR for recovery 1.16, 95\% CI 1.01-1.32). Among the 216 patients who were on high-flow oxygen or non-invasive ventilation at baseline, the median recovery time in the group receiving baricitinib was 10 days versus 18 with placebo (RR $1.51,95 \% \mathrm{CI}$ 1.10-2.08). However, among the 223 patients who were also on glucocorticoids during the trial, no difference in recovery time was detected [52].

Moreover, an observational retrospective study included 43 hospitalized patients with severe COVID-19 managed with everyday baricitinib for six days duration. Baricitinab showed a significant statistical clinical improvement ( $p$-value $<0.01$ ) in addition to a $100 \%$ survival rate after one month and two months. The average recovery time was 12 days from the beginning of baricitinab. This drug was found to be safe with no side effects associated with baricitinib, and there was a statistically significant improvement at day 14 for all poor prognostic factors like Interleukin-6, serum ferritin, platelet, lymphocyte count, D-dimer, and C-reactive protein $(p$-value < 0.05) [53].

\subsubsection{Corticosteroids}

Corticosteroids are a branch of steroid hormones that are produced in the adrenal cortex of vertebrates. They are classified into two major classes: glucocorticoids and mineralocorticoids. They play essential roles in many physiological processes. Several examples include their function in stress response, immune response, regulation of inflammation, carbohydrate metabolism, and protein catabolism. The most dominant naturally occurring steroid hormones are corticosterone, cortisone, aldosterone, and cortisol. The adrenal cortex produces the main corticosteroids (cortisol and aldosterone) [54].

In the SARS pandemic, corticosteroids had demonstrated no survival benefit and possible harm on patients. For this reason, the WHO discouraged the utilization of corticosteroids for COVID-19 patients [55-57]. However, in China, they observed that using corticosteroids reduced the mortality rate among COVID-19 patients, so the interest in utilizing the corticosteroids was renewed and recommendations began to support the use of corticosteroids, namely dexamethasone, in the treatment of SARS-CoV-2 patients [15,58-63]. This paradigm shift was largely due to data from randomized trials that overall supported the role of glucocorticoids. In a meta-analysis of seven trials that included 1703 critical COVID-19 patients, glucocorticoids reduced 28-day mortality compared with standard 
care or placebo (32 versus 40 percent, odds ratio [OR] 0.66, 95\% CI 0.53-0.82) and were not associated with an increased risk of severe adverse events [9]. Another systematic review and network meta-analysis of randomized trials through mid-August 2020 found that glucocorticoids were the only intervention with at least moderate certainty in a mortality reduction (OR $0.87,95 \%$ CI $0.77-0.98$ ) or risk of mechanical ventilation (OR 0.74, 95\% CI 0.58-0.92) compared with standard care [64]. Most of the efficacy data on glucocorticoids in these meta-analyses are based on a large, randomized, open-label trial in the United Kingdom in which oral or intravenous dexamethasone reduced 28-day mortality among hospitalized patients compared with usual care alone [65]. Other glucocorticoids were also investigated. Individual trials of hydrocortisone in critically ill patients failed to demonstrate benefit $[66,67]$. Meta-analysis of three trials evaluating hydrocortisone found a non-statistically significant trend towards reduced 28-day mortality compared with usual care or placebo (OR 0.69, 95\% CI 0.43-1.12) [9]. Furthermore, trials that evaluated the use of methylprednisone found no clear benefit. A randomized trial from Brazil, including 393 patients with suspected or confirmed severe COVID-19 (77 percent of whom were on oxygen or ventilatory support), found no difference in 28-day mortality rates with methylprednisone compared with placebo (37 versus 38 percent) [68]. Inhaled corticosteroids were also investigated as potential agents that may be of benefit in the outpatient setting. In the non-placebo-controlled steroids in COVID-19 (STOIC) trial, 139 adult patients with mild early COVID-19 were treated with inhaled budesonide $(800$ mcg twice daily) for an average of seven days or assigned usual care. Fewer patients in the group treated with inhaled budesonide required urgent medical evaluation or hospitalization at 28 days (1.4 versus 14.4 percent), reflecting a possible role of inhaled corticosteroids in the outpatient setting [69]. However, in the same context, a recent study demonstrated that treatment of COVID-19 patients with corticosteroids did not affect hospital mortality rate [70]. In comparison with patients who did not receive corticosteroids, the positive impact associated with their utilization was a decline in ICU admission rate. Nevertheless, steroids can enhance compliance and hypoxemia in ARDS patients [71]. In this sense, treatment with steroids may help reduce pressure on the Intensive Care Units [70].

\subsubsection{Vitamin D}

Vitamin D deficiency is an increasing global public health issue, and the effects of low vitamin $\mathrm{D}$ levels are being explored in a variety of clinical settings, including respiratory viral diseases. Several studies in both children and adults have found an inverse relationship between vitamin $\mathrm{D}$ levels and the severity and mortality of respiratory viral infections [72-75]. A study revealed that individuals with positive PCR for SARS-CoV-2 had a low 25-hydroxyvitamin D 25-OHD level in comparison with individuals with a negative PCR [76]. Additionally, the concentration of 25-OHD in serum was lower in severe cases and higher in moderate cases $[77,78]$. Since then, many studies have suggested that supplementation of vitamin D may play a potential role in Covid-19 treatment. Numerous trials have been started to examine the efficacy of vitamin $\mathrm{D}$ as supplementation in the treatment of Covid-19 patients. The pathway by which vitamin D influences the pathogenesis of COVID-19 is still unclear. However, many hypotheses that explained the influence of vitamin D in COVID-19 pathogenesis have been suggested [79]. The deficiency of glucose-6-phosphate dehydrogenase enhances viral replication. Furthermore, G6PD deficiency can increase the infectiousness of human Coronavirus 229E [80], due to the critical role of G6PD in cellular redox state. Nevertheless, the expression of the G6PD gene is enhanced by vitamin D, so vitamin D can also possibly affect COVID-19 pathogenesis indirectly [81].

One of the major factors affecting morbidity and mortality in COVID-19 is inflammatoryrelated disorders [82]. The pro-inflammatory responses in viral infection may be minimized by vitamin D due to several pathways, including (i) selective suppression of inflammatory cytokines, (ii) decreased influx of leukocytes into inflammatory regions [75], (iii) immune cells including neutrophils, monocytes/macrophages and mast cell interplay with vitamin 
D [83], (iv) vitamin D can also help to boost memory and regulatory T-cells [84], (v) Activity of T lymphocytes is influenced by vitamin $\mathrm{D}$ [85].

A randomized, placebo-controlled study found that vitamin D reduces recovery time in COVID-19 cases. Furthermore, there was a substantial reduction in inflammatory markers [86]. A quasi-experimental study reported that vitamin D supplementation reduced the severity of disease and improved the survival rate within elderly COVID-19 patients [87]. On another hand, a placebo-controlled trial failed to find any significant association between vitamin D supplementation and reduction in recovery time for COVID-19 [88], and a randomized trial from Brazil evaluating a single dose of vitamin D3 (200,000 international units) versus placebo in 240 moderately ill hospitalized COVID-19 patients (mean baseline 25[OH]D $20.9 \mathrm{ng} / \mathrm{mL}$ [52 nmol/L]) found no difference in length of hospital stay, and no significant differences in secondary outcomes such as in-hospital mortality (7.6 versus 5.1 percent, mean difference 2.5 percent, $95 \% \mathrm{CI}-4.1$ to 9.2 percent), admission to the ICU (16 versus 21.2 percent, mean difference -5.2 percent, $95 \% \mathrm{CI}-15.1$ to 4.7 percent), or need for mechanical ventilation (7.6 versus 14.4 percent, mean difference -6.8 percent, $95 \%$ CI -15.1 to 1.2 percent) [88]. Nevertheless, several larger placebo-controlled trials evaluating the role of vitamin D are still in progress $[89,90]$.

There is a debate about the benefit of using vitamin D to treat cases of COVID-19, as there are many studies that suggest a benefit from vitamin D use, while other studies reported no association. Currently, there is no conclusive evidence of a relationship between vitamin D levels and decreased mortality in COVID-19 patients [91].

\subsubsection{Interleukin-6 (IL-6) Pathway Inhibitors (e.g., Tocilizumab)}

Markedly elevated inflammatory markers (e.g., D-dimer, ferritin) and elevated levels of pro-inflammatory cytokines (including interleukin [IL]-6) are associated with critical and fatal COVID-19 cases. Accordingly, it was suggested that mortality may be due to virally driven hyper inflammation [92]. A retrospective multicenter study on 150 confirmed COVID-19 cases in Wuhan, China, found that levels of ferritin $(p<0.001)$ and IL-6 $(p<0.0001)$ were higher in non-survivors compared with survivors and described such elevations to be predictors of mortality [93]. Preliminary results from an open-label international randomized trial that included 803 patients with severe COVID-19 who were admitted to the ICU and required respiratory or cardiovascular support suggest a mortality benefit of interleukin-6 pathway inhibitors [94]. In another 2021 trial that included 389 hospitalized patients with COVID-19 who were not on ventilatory support, tocilizumab reduced progression to mechanical ventilation or death at 28 days but not overall 28-day mortality [95]. Despite optimistic emerging preliminary evidence, several studies failed to show clear clinical benefit or reduced mortality associated with the use of interleukin-6 pathway inhibitors [95-99]. Trials that suggested a benefit with tocilizumab reported somewhat higher overall mortality rates when viewed in comparison with other trials, which may be interpreted to be a sign reflecting more severely affected populations. The National Institutes of Health (NIH) COVID-19 Treatment Guidelines Panel currently recommends adding tocilizumab to dexamethasone in recently hospitalized patients on high-flow oxygen or greater support that have either been admitted to the ICU within the prior $24 \mathrm{~h}$ or have significantly increased levels of inflammatory markers [58]. Moreover, the Infectious Diseases Society of America (IDSA) currently suggests adding tocilizumab to the standard of care (i.e., glucocorticoids) for hospitalized adults who have progressive severe or critical COVID-19 and have elevated markers of systemic inflammation [100].

\subsubsection{Interleukin-1 Pathway Inhibitors (e.g., Anakinra)}

Interleukin-1 (IL-1) is a pro-inflammatory cytokine that has been associated with severe COVID-19. Several observational studies suggested that using IL-1 inhibitors such as anakinra is associated with reduced mortality in COVID-19 patients [101-104]. On the other hand, a randomized trial of 116 hospitalized patients with mild to moderate COVID19 found no evidence of clinical benefit of anakinra addition to usual care compared 
with usual care alone and no statistically significant reduction in the rates of mechanical ventilation or death at 14 days was detected (34 versus 35 percent, respectively) [105].

However, a meta-analysis with 757 patients treated with anakinra while 2773 patients treated with standard non-anakinra management found that the usage of anakinra for treatment of COVID-19 patients was associated with a significant reduction in demand of mechanical ventilation and mortality rate compared with standard non-anakinra management. Although the anakinra group had slightly more risk of thromboembolism $(\mathrm{OR}=1.59)$ and elevated liver transaminases enzymes $(\mathrm{OR}=1.35)$ than the other group, these risks were not statistically significant, and the difference may be due to the characteristics of the control group [106].

More data from larger randomized trials are required to better understand the role of IL-1 inhibitors in the clinical resolution of COVID-19, in addition to resolving dosing procedures and potential side effects.

\subsubsection{Interferons (e.g., Interferon Beta)}

Interferons function by modulation of immune responses and have been described to have antiviral effects [107]. Interferon-beta (IFN- $\beta$ ), specifically, has been reported to inhibit SARS-CoV-2 replication in vitro [108]. Furthermore, defects in the production of type I interferons (which include IFN- $\beta$ ) and autoantibodies that neutralize type I interferons have been identified in patients with severe COVID-19 [109,110]. Interim results of the WHO Solidarity Trial showed no difference in 28-day mortality with subcutaneous or intravenous interferon beta compared with usual care (2703 patients in each group; RR 1.16, 95\% CI 0.96-1.39) [48]. Smaller trials reported clinical improvement, faster discharge times, and a potential mortality benefit with interferon beta [104]. However, methodologic limitations in such studies invoke reservations [111].

In addition, the debate about the effectiveness of IFN as a treatment for COVID-19 patients was due to the differences in the COVID-19 severity determination, time of IFN administration, and how the researchers read the test results either direct IFN effect or cellular reactions to IFNs [112]. In a retrospective cohort study with 446 COVID-19 patients in Hubei, China, they found that early initiation of IFN on the first five days of their hospital admission had a shorter hospitalization duration ( $p$-value was 0.001), early improvement of CT scan findings ( $p$-value was 0.001), and short COVID-19 duration from the beginning of symptoms to the end of hospitalization ( $p$-value was 0.025 ). On the other hand, the delay in INF administration slowed recovery and increased mortality [113]. IT was also found that the prolonged administration of IFN therapy can lead to regeneration impairment or damage for the lung epithelium, and second bacterial infection superimposed COVID-19 infection, which may be lethal [113]. Accordingly, Jack Major et al. recommended usage of IFN treatment or prophylaxis by early strong administration of IFN to stop viral replication, followed by INF down-regulation to enhance regeneration of lung epithelium. The duration and timing of IFN administration are crucial for optimal effect, but more clinical studies regarding the efficacy and safety of using IFN for COVID-19 treatment are needed [114].

\subsubsection{Ivermectin}

Ivermectin, a drug first discovered in a golf course in Japan by microbiologist Satoshi Omura in 1970, is one of the best-known antiparasitic drugs for its efficacy in treating a broad spectrum of parasitic infections [115]. In vitro studies on ivermectin at doses that far exceed those achieved in vivo with safe doses displayed in vitro activity against SARSCoV-2, and thus it has been proposed as a potential therapy in COVID-19 [116]. Kaur et al. used artificial intelligence to study the interaction between ivermectin and SARS-CoV-2 proteins. They found a positive interaction between this drug and the viral proteins, which means it may have beneficial outcomes for COVID-19 patients [117]. In a retrospective review that included 280 hospitalized COVID-19 patients, administration of ivermectin was associated with a lower mortality rate. However, such patients were also more likely 
to receive corticosteroids, and thus, randomized studies are required to ascertain such positive effects in the absence of potential confounders [118].

\subsubsection{Favipiravir}

Favipiravir is an RNA polymerase inhibitor licensed as an anti-influenza drug in Japan [119]. Favipiravir can effectively inhibit the RNA-dependent RNA polymerase of viruses such as influenza, Ebola, and norovirus [120]. Studies in Vero E6 cells have suggested that favipiravir can deactivate the SARS-CoV-2 virus (Figure 3) [31]. Early trials in which favipiravir was administered alongside other agents (e.g., immunomodulatory drugs) in Russia [121] and China [122] suggested some benefits. The role of favipiravir in COVID-19 treatment is being evaluated in clinical trials in the United States and elsewhere.

\section{Favipiravir}

Potential repurposed drug candidate for COVID-19

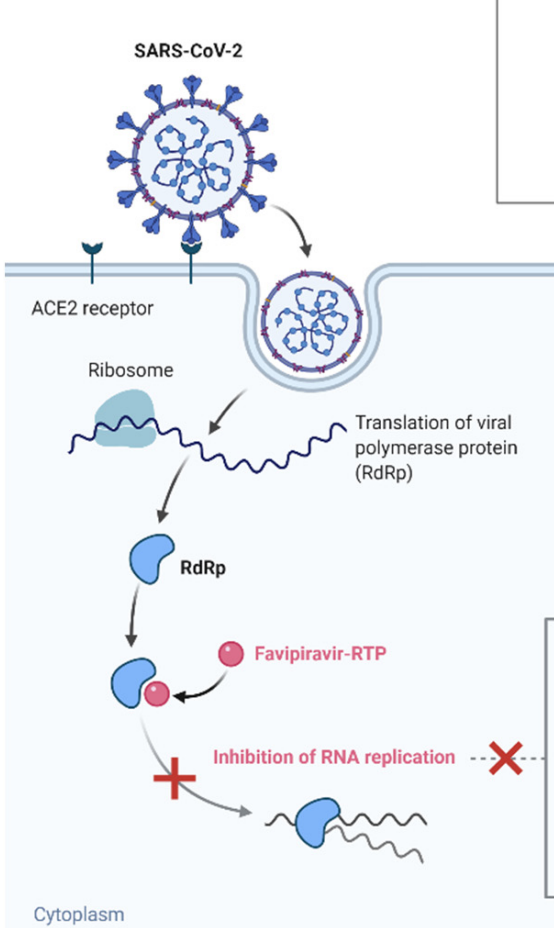<smiles>NC(=O)c1nc(F)cnc1O</smiles>

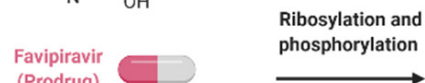

(Prodrug)

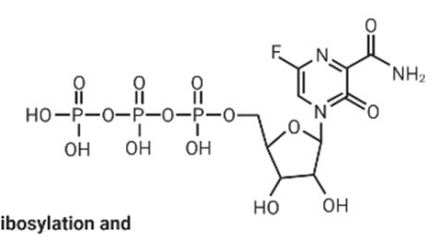

Favipiravir-RTP (Active molecule)

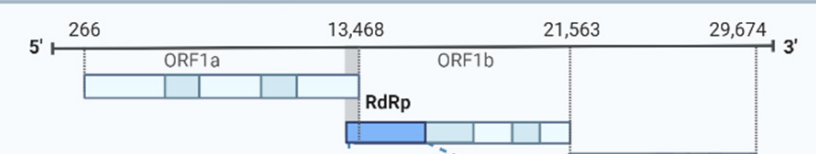

Genomic replication m

Subgenomic (nested) transcription

$\sim$ Nucleocapsid (N)

$\sim$ Spike (S)

$\sim$ Membrane (M) OP

$\sim$ Envelope (E)

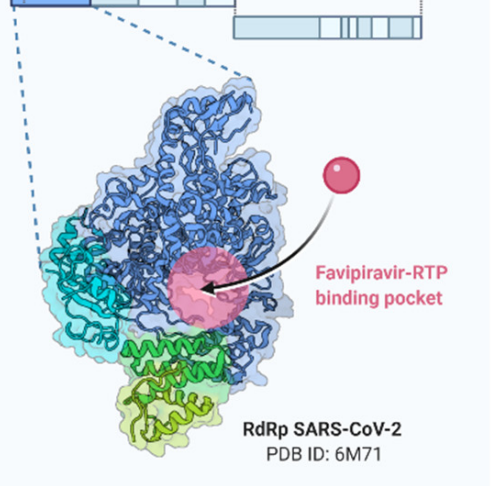

Figure 3. The mechanisms of action of Favipiravir against coronaviruses. (Created with BioRender. com, accessed on 10 January 2022).

In a study with a total of 1489 Turkish patients, favipiravir alone was used in 537 patients while hydroxychloroquine alone was used in 545 patients, and a combination of both favipiravir and hydroxychloroquine was used for the rest of the patients. On the fourteenth day of follow-up, patients who were treated with hydroxychloroquine had improvement of COVID-19 symptoms by 1.8-fold greater than patients who were treated with favipiravir alone. There was a similarity in the rate of hospitalization among patients who were treated with hydroxychloroquine and favipiravir. However, among patients who had pneumonia at the time of COVID-19 diagnosis, those who were treated with hydroxychloroquine alone had a hospitalization rate of 6.6-fold less than patients who were treated with favipiravir alone and by 7.3-fold less than patients who were treated with the combination of drugs [123]. 


\subsubsection{Molnupiravir (Lagevrio)}

Molnupiravir is an oral antiviral that has activity like Remdesivir and favipiravir. It can effectively inhibit the RNA-dependent RNA polymerase of viruses such as influenza and alphavirus infections [124-126]. Accordingly, the utility of molnupiravir in COVID-19 treatment is being evaluated by several researchers.

In a large systemic review, a daily dose of 1600 milligram molnupiravir for 5.5 days, which was safe with no significant side effects, can significantly decrease COVID-19 mortality rate at day 29 by 50\% as well as decreased the hospitalization rate for mild COVID-19. There was no significant impact in moderate or severe COVID-19 infection [125]. Additionally, there was no effect of SARS-CoV-2 variants, symptoms onset time, or patients' risk factors on the efficacy of molnupiravir [125]. Molnupiravir can also effectively decrease the nasopharyngeal SARS-CoV-2 virus and viral RNA isolation at day 3 and no virus was isolated at day 5 of administration [126,127].

As a result, the medicines regulator in the United Kingdom was the first country that approved molnupiravir for the management of adults with mild to moderate COVID-19 and has any risk factors for severe infection [128]. Subsequently, it has been approved in several countries such as the United States, Canada, China, Japan, Korea, and the Europe Union [129]. Moreover, molnupiravir was the first antiviral drug that can be taken orally, which is a significant advantage [129-131]. However, some experts have suggested that molnupiravir should be used for COVID-19 patients outside the hospital, while Remdesivir is the preferred choice for COVID-19 patients under hospital care [129].

\subsubsection{Lopinavir-Ritonavir}

Co-formulated lopinavir-ritonavir is a boosted protease inhibitor (PI) that contains lopinavir and low-dose ritonavir. It is approved for use in combination with other antiretroviral drugs for the treatment of HIV in the United States and the European Union [130]. Several clinical trials demonstrated no efficacy of lopinavir-ritonavir in the treatment of COVID-19 patients $[65,113,132,133]$. One such study, which was an open-label randomized trial of hospitalized COVID-19 patients, found that lopinavir-ritonavir administration for up to 10 days did not reduce 28-day mortality or 28-day discharge rates, or the need for mechanical ventilation when compared with usual care (Figure 4) [134].

\subsubsection{Sofosbuvir Plus Daclatasvir}

The role of concomitant use of Hepatitis $\mathrm{C}$ virus $(\mathrm{HCV})$ antivirals sofosbuvir and daclatasvir has been explored in small-scale studies [131,132,135] One such study described that the addition of sofosbuvir and daclatasvir to standard care significantly reduced the duration of hospital stay compared with standard care alone [131]. Larger randomized trials are needed to fully understand the potential role of such agents in the management of COVID-19.

\subsubsection{Azithromycin}

The macrolide antibiotic azithromycin has been proposed as a potential agent in the treatment of COVID-19 based on its immunomodulatory actions [133]. Several studies that evaluated the use of azithromycin alone or with hydroxychloroquine found no clinical benefit of its use in COVID-19 [35,133,136-140]. 


\section{Lopinavir}

Potential repurposed drug candidate for COVID-19

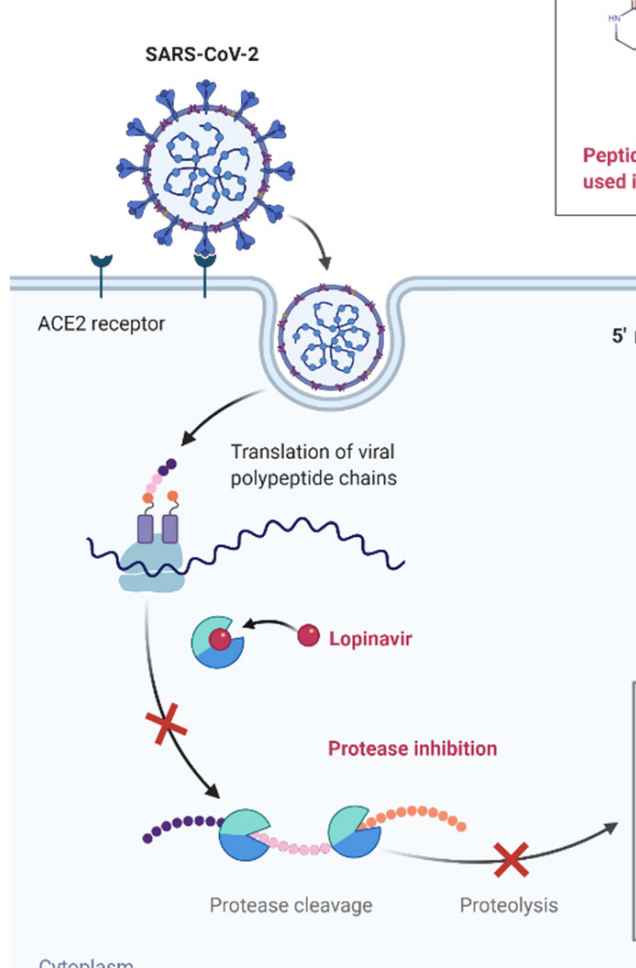

Cytoplasm
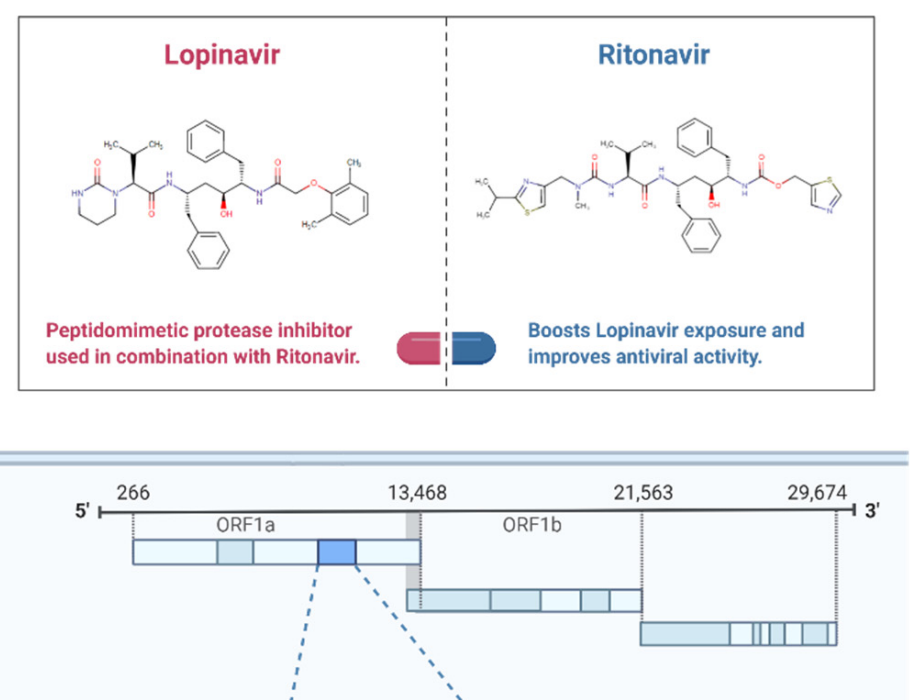

3CL-protease SARS-CoV
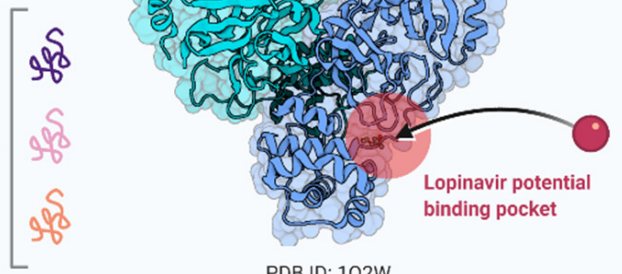

PDB ID: 1Q2W

Figure 4. The mechanisms of action of lopinavir against coronaviruses. (Created with BioRender.com, accessed on 10 January 2022).

\subsubsection{Colchicine}

The role of colchicine in the treatment of hospitalized COVID-19 patients was also investigated [141]. In March 2021, the RECOVERY trial closed recruitment to its randomized clinical trial that compared colchicine to usual care alone, which started in November 2020. The RECOVERY trial independent Data Monitoring Committee (DMC) recommended this action, saying that "The DMC saw no convincing evidence that further recruitment would provide conclusive proof of worthwhile mortality benefit either overall or in any pre-specified subgroup" [142].

On the contrary, a meta-analysis showed that colchicine had a clear positive outcome in reducing mortality in COVID-19 patients. This conclusion is based on a small number of papers and patients, which maybe not be sufficient to be a definitive outcome [143].

\subsubsection{Fluvoxamine}

Limited data suggest that the selective serotonin reuptake inhibitor (SSRI) fluvoxamine may reduce progression to severe disease in early mild cases of COVID-19 [144,145]. Until now, fluvoxamine combined with physical therapy had a positive impact among COVID-19 patients in ICU [146]. However, large scale high-quality randomized trials are required to fully assess the potential of fluvoxamine in the battle against COVID-19 in outpatient and hospital settings.

\section{Convalescent Plasma Therapy}

While many studies conducted worldwide suggest that elderly individuals and patients with chronic disease, especially those with chronic lung disease, are at higher risk of 
developing SARS-CoV-2-related pneumonia (COVID-19) and respiratory failure [147], little information is available to elucidate whether immunocompromised patients or patients receiving immunosuppressive treatment are at higher risk. A systematic review article published in July 2020 evaluating 16 articles with 110 immunocompromised patients infected with SARS-CoV-2 suggested that both children and adults with immunosuppression seem to have a favorable disease when compared to the general population [148] However, an alarming report by Tepasse et al., described fatally persisting viremia without any sign of viral clearance in two patients who received rituximab two weeks before infection with SARS-CoV-2, suggesting that due to its effect that leads to complete B-cell depletion, rituximab may be associated with severe COVID-19 outcomes [149]. Interestingly, a case report by Clark et al. demonstrated rapid clinical improvement followed by viral clearance after administration of hyperimmune plasma in a hospitalized COVID-19 patient who had recently been treated with rituximab [150].

In the general population, several observational studies suggested great clinical benefit with early administration of high-titer convalescent plasma [151-153]. In the outpatient setting, a randomized, double-blind, placebo-controlled trial with high IgG titer convalescent plasma was given within $72 \mathrm{~h}$ after the onset of mild COVID-19 symptoms to certain highrisk adult outpatients (age $\geq 75$ years or $\geq 65$ years with one or more specific comorbidities [hypertension, chronic obstructive lung disease, diabetes mellitus on pharmacotherapy, cardiovascular disease, chronic renal failure, obesity]), found that early administration of high-titer convalescent plasma reduced the progression to severe disease [154]. However, randomized trials in hospitalized COVID-19 patients failed to demonstrate a clear clinical benefit of convalescent plasma [155-158]. One such placebo-controlled trial from Argentina included 333 cases with severe COVID-19 and found no statistically significant differences in clinical status at 30 days (adjusted odds ratio $0.92,95 \%$ CI $0.59-1.42$ ) or in 30-day mortality (10.96 versus 11.43 percent, risk difference -0.46 percent, $95 \%$ CI $-7.8-6.8$ ) between convalescent plasma (with a median total antibody titer of 1:3200) and placebo [158]. On February 4, the United States Food and Drug Administration (FDA) issued a revision of its original emergency use authorization (EUA) for the use of COVID-19 convalescent plasma that limits the authorization to the use of high titer COVID-19 plasma for the treatment of hospitalized patients in the early disease course [159]. It may also be useful in the reduction of hospital stay duration, mortality, the severity of symptoms, and even the recurrence of the side effects. Moreover, there is no definitive or strong significance about using this method in treatment [160].

\section{Monoclonal Antibody Therapy (e.g., Bamlanivimab-Etesevimab; Casirivimab-Imdevimab)}

Like SARS-CoV and MERS-CoV, SARS-CoV-2 is an enveloped, single-stranded, and positive-sense RNA virus. SARS-CoV-2 is phylogenetically related to SARS-CoV, sharing approximately $79.6 \%$ genomic sequence identity [161]. Similar to other emerging pathogenic human coronaviruses, the genome of SARS-CoV-2 encodes the spike (S) protein, which plays an essential role in viral attachment, fusion, entry, and transmission. The spike protein comprises an $\mathrm{N}$-terminal $\mathrm{S} 1$ subunit responsible for virus-receptor binding and a C-terminal S2 subunit responsible for virus-cell membrane fusion. S1 is further divided into an N-terminal domain (NTD) and a receptor-binding domain (RBD). SARS-CoV-2 binds Angiotensin-converting enzyme 2 (ACE2) [162-164]. Virus neutralizing antibodies (nAbs) induced by vaccines or prior infection play crucial roles in controlling viral infection. Currently developed SARS-CoV and MERS-CoV-specific nAbs include monoclonal antibodies [165]. They target S1-RBD, S1-NTD, or the S2 region, thereby blocking the binding of RBDs to their respective receptors and interfering with S2-mediated membrane fusion or entry into the host cell $[164,166]$. SARS-CoV2-specific nAbs that target the host ACE2 receptor-binding domain show promise therapeutically [167-171] and are under clinical evaluation [172-175]. 
In November 2020, the United States FDA issued an emergency use authorization (EUA) for the use of basiliximab-imdevimab, which are investigational recombinant human IgG1 monoclonal antibodies that target the receptor-binding domain of the spike protein of SARS-CoV-2 [176]. On 9 February 2021, the U.S. FDA issued a EUA for the use of bamlanivimab-etesevimab, which are investigational neutralizing IgG1 monoclonal antibodies that bind to distinct but overlapping epitopes within the receptor-binding domain of the spike protein of SARS-CoV-2 [177]. Both EUAs were limited to combinational use only (e.g., bamlanivimab-etesevimab as opposed to either agent alone) in the treatment of mild to moderate COVID-19 in adults and pediatric patients (12 years of age and older weighing at least $40 \mathrm{~kg}$ ) with positive results of direct SARS-CoV-2 viral testing, and who are at considerable risk for progressing to severe COVID-19 and/or hospitalization. The National Institutes of Health (NIH) treatment guidelines panel currently recommends treatment with combination bamlanivimab-etesevimab or casirivimab-imdevimab in high-risk outpatients as defined by the FDA EUA criteria [58]. The Infectious Disease Society of America (IDSA) currently recommends treatment only with bamlanivimab-etesevimab for such patients due to more limited data on the efficacy of casirivimab-imdevimab [178].

In phase 2/3 of BLAZE-1, a randomized controlled trial that included 577 patients with mild to moderate illness, different doses of bamlanivimab monotherapy, and combination bamlanivimab-etesevimab therapy were compared with placebo. At one month, treatment with combination therapy resulted in a small, statistically significant reduction in combined rates of emergency department visits or hospitalization (IRR 4.9\%, 95\% CI -8.9 to -0.8 ), and among participants who were $\geq 65$ years of age or had a BMI $\geq 35 \mathrm{~kg} / \mathrm{m}^{2}$, the risk of hospitalization with combination antibody therapy compared with placebo was significantly reduced (0 versus 13.5 percent) [179]. Furthermore, in an unpublished, preliminary report of results from a randomized controlled trial that included 4180 non-hospitalized adults with mild to moderate COVID-19, combination casirivimab-imdevimab, at two different doses, was compared with placebo. At 29 days, among patients with certain risk factors for severe COVID-19, there was a reduction in the combined outcome of hospitalizations and death among those treated with both doses of casirivimab-imdevimab compared with placebo (1200 mg total dose, 1 versus 3.2 percent; $2400 \mathrm{mg}$ dose, 1.3 versus 4.6 percent) $[180,181]$. On the other hand, a randomized study that assigned 314 hospitalized patients who had COVID-19 without end-organ failure to either bamlanivimab or placebo found that the percentage of patients with the primary safety outcome was similar in the bamlanivimab group and the placebo group (19\% and $14 \%$, respectively; odds ratio, 1.56 ; 95\% CI, 0.78 to $3.10 ; p=0.20$ ) [182].

The potency and safety of monoclonal therapy for children and teenagers are not proven, with inadequate evidence for some advantages among adult COVID-19 patients. Accordingly, a panel of pediatric infectious specialists recommended not to use monoclonal antibody therapy in children and teenager COVID-19 patients. Hypersensitivity and infusion reactions are possible side effects of this therapy [183].

Overall, further data is required to fully assess the possible role for monoclonal antibodies, and specifically, bamlanivimab-etesevimab and casirivimab-imdevimab, in the treatment of COVID-19 in different populations at outpatient and hospital settings.

\section{Vaccines against COVID-19}

Vaccinations are considered one of the most impactful inventions in medicine. Despite the success of many vaccines, new pandemics started at the end of the 20th century and the beginning of the 21st century, such as Human immunodeficiency virus (HIV) and SARS-CoV-2, respectively [184]. During the SARS-CoV-2 pandemic, several vaccines have been developed, and they are under continuous evaluation (Table 1). The WHO started the first vaccination program in December 2020, and at the time of this manuscript preparation, more than 983.1 million vaccine doses have been given worldwide [185]. Various generic platforms were used to develop the vaccines, such as using viral protein, Adenovirusvectored vaccines, using an inactivated virus, mRNA, or RNA-based vaccine [184]. 
Table 1. Status of COVID-19 Vaccines until 30 November 2021 [184,186-196].

\begin{tabular}{|c|c|c|c|c|c|c|}
\hline & Manufacturer & Name of Vaccine & Platform & $\begin{array}{c}\text { Dossier } \\
\text { Accepted for } \\
\text { Review }\end{array}$ & $\begin{array}{c}\text { Status of } \\
\text { Assessment }\end{array}$ & $\begin{array}{c}\text { Predicted } \\
\text { Decision Date } \\
* * *\end{array}$ \\
\hline 1 & $\begin{array}{l}\text { Pizen } \\
\text { BIONTEC-1 }\end{array}$ & $\begin{array}{l}\text { BNT162b2/COMIRNATY } \\
\text { Tozinameran (INN) }\end{array}$ & $\begin{array}{l}\text { Nucleoside modified } \\
\text { mRNA. }\end{array}$ & $\sqrt{ }$ & Finalized & $\begin{array}{l}31 \text { December } \\
2020\end{array}$ \\
\hline 2 & AstraZeneca 2 & AZD1222 & $\begin{array}{c}\text { Recombinant } \\
\text { ChAdOx1 adenoviral } \\
\text { vector encoding the } \\
\text { Spike protein antigen } \\
\text { of the CoV. }\end{array}$ & $\begin{array}{c}\text { Accepted core } \\
\text { data of AZ- } \\
\text { non-COVAX. } \\
\text { Data for Covax } \\
\text { is expected in } \\
\text { April } 2021 .\end{array}$ & $\begin{array}{c}\text { Core } \\
\text { data-now as a } \\
\text { donation for } \\
\text { COVAX. } \\
\text { Awaited }\end{array}$ & $\begin{array}{l}15 \text { April } 2021 \\
\text { April } 2021\end{array}$ \\
\hline 3 & $\begin{array}{l}\text { SKBIO } \\
\text { Astrazeneca } 8 \\
\text { OXFORD }\end{array}$ & AZD1222 & $\begin{array}{c}\text { Recombinant } \\
\text { ChAdOx1 adenoviral } \\
\text { vector encoding the } \\
\text { Spike protein antigen } \\
\text { of the CoV. }\end{array}$ & $\sqrt{ }$ & Finalized & $\begin{array}{l}15 \text { February } \\
2021\end{array}$ \\
\hline 4 & $\begin{array}{l}\text { Serum Institute } \\
\text { of India }\end{array}$ & $\begin{array}{c}\text { Covishield } \\
\text { (ChAdOx1_nCoV19) }\end{array}$ & $\begin{array}{l}\text { Recombinant } \\
\text { ChAdOx1 adenoviral } \\
\text { vector encoding the } \\
\text { Spike protein antigen } \\
\text { of the SARS-CoV-2. }\end{array}$ & $\sqrt{ }$ & Finalized & $\begin{array}{l}15 \text { February } \\
2021\end{array}$ \\
\hline 5 & Sinopharm/BIBP1 & $\begin{array}{c}\text { SARS-CoV-2 Vaccine } \\
\text { (Vero } \\
\text { Cell), Inactivated } \\
\text { (lnCoV) }\end{array}$ & $\begin{array}{c}\text { Inactivated, } \\
\text { produced in Vero } \\
\text { cells. }\end{array}$ & $\sqrt{ }$ & In progress & $\begin{array}{c}\text { Finish in April } \\
2021\end{array}$ \\
\hline 6 & $\infty_{\text {sinovac. }}$ & $\begin{array}{c}\text { SARS-CoV-2 Vaccine } \\
\text { (Vero } \\
\text { Cell), Inactivated }\end{array}$ & $\begin{array}{c}\text { Inactivated, } \\
\text { produced in Vero } \\
\text { cells. }\end{array}$ & $\sqrt{ }$ & In progress & Early May 2021 \\
\hline 7 & moderna & mRNA-1273 & $\begin{array}{c}\text { mRNA-based } \\
\text { vaccine encapsulated } \\
\text { in a lipid } \\
\text { nanoparticle (LNP). }\end{array}$ & $\sqrt{ }$ & In progress & End April 2021 \\
\hline 8 & Janssen Intectious Diseases & Ad26.COV2.S & $\begin{array}{c}\text { Recombinant, } \\
\text { replication- } \\
\text { incompetent } \\
\text { adenovirus type } 26 \\
\text { (Ad26) vectored } \\
\text { vaccine encoding the } \\
\text { (SARS-CoV-2) Spike } \\
\text { (S) protein. }\end{array}$ & $\sqrt{ }$ & Finalized & $\begin{array}{l}12 \text { March } 2021 \\
\text { For fixing after } \\
\text { submission of } \\
\text { data }\end{array}$ \\
\hline 9 & 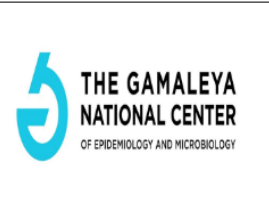 & Sputnik V & $\begin{array}{l}\text { Human Adenovirus } \\
\text { Vector-based } \\
\text { COVID-19 vaccine. }\end{array}$ & $\begin{array}{l}\text { "Rolling" } \\
\text { submission of } \\
\text { clinical and } \\
\text { CMC data has } \\
\text { started. }\end{array}$ & $\begin{array}{l}\text { Additional data } \\
\text { is required. }\end{array}$ & $\begin{array}{l}\text { Will be fixed } \\
\text { after all data is } \\
\text { submitted and } \\
\text { completed. }\end{array}$ \\
\hline
\end{tabular}


Table 1. Cont.

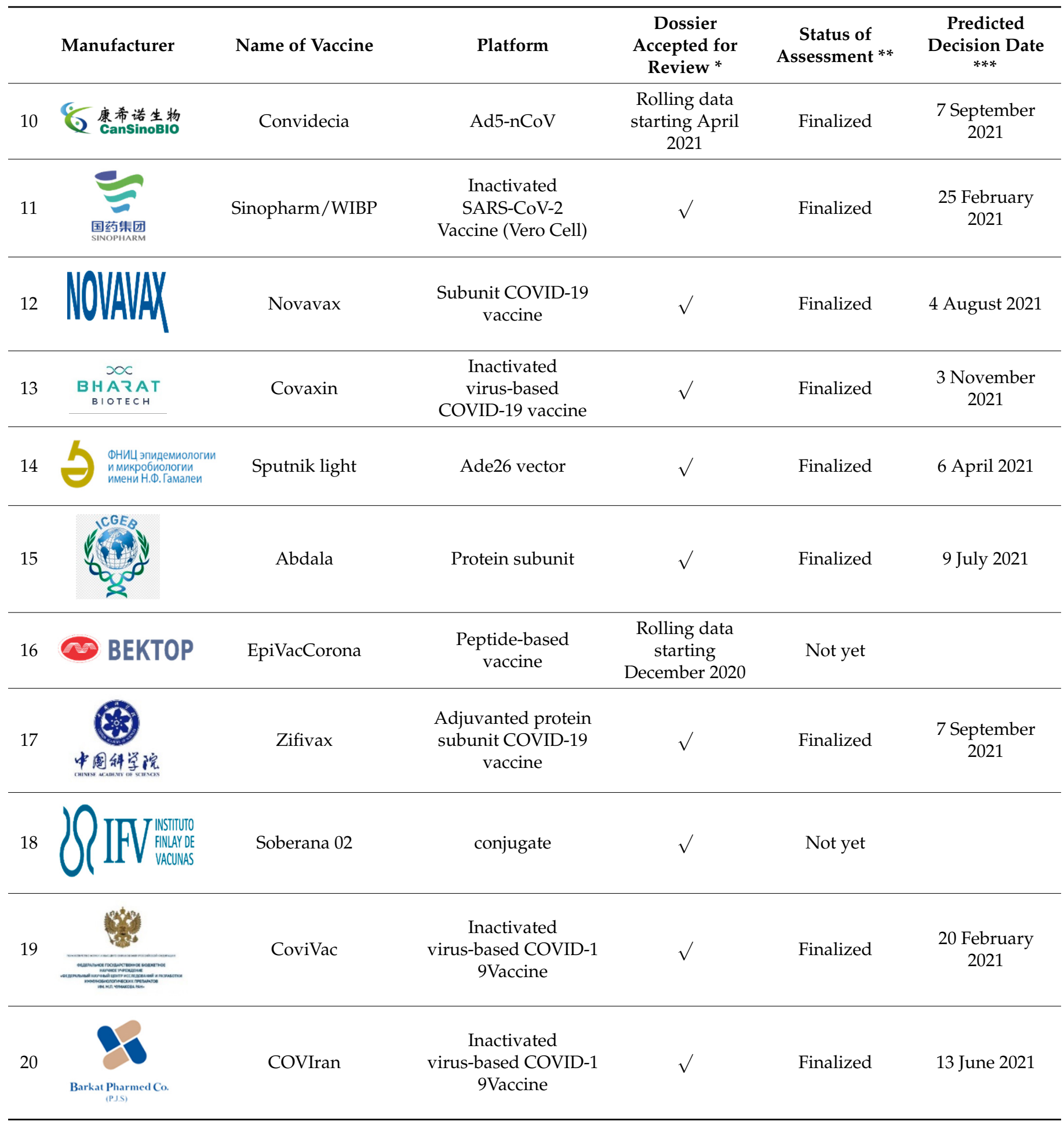


Table 1. Cont.

\begin{tabular}{|c|c|c|c|c|c|c|}
\hline & Manufacturer & Name of Vaccine & Platform & $\begin{array}{c}\text { Dossier } \\
\text { Accepted for } \\
\text { Review }\end{array}$ & $\begin{array}{c}\text { Status of } \\
\text { Assessment }\end{array}$ & $\begin{array}{c}\text { Predicted } \\
\text { Decision Date } \\
* * *\end{array}$ \\
\hline 21 & & $\begin{array}{l}\text { Chinese Academy of } \\
\text { medical sciences } \\
\text { COVID-19 vaccine } \\
\text { (IMBCAMS COVID-19 } \\
\text { VACCINE) }\end{array}$ & $\begin{array}{c}\text { Inactivated } \\
\text { virus-based COVID-1 } \\
\text { 9Vaccine }\end{array}$ & $\sqrt{ }$ & Finalized & 9 June 2021 \\
\hline 22 & & MVC COVID-19 vaccine & $\begin{array}{l}\text { Protein-subunit } \\
\text { COVID-19 vaccine }\end{array}$ & $\sqrt{ }$ & Not yet & \\
\hline 23 & & ZyCoV-d & $\begin{array}{l}\text { DNA plasmid-based } \\
\text { Covid-19 vaccine }\end{array}$ & $\sqrt{ }$ & Finalized & 1 July 2021 \\
\hline 24 & & FAKHRAVAC & $\begin{array}{c}\text { Inactivated } \\
\text { virus-based COVID-1 } \\
\text { 9Vaccine }\end{array}$ & $\sqrt{ }$ & Finalized & $\begin{array}{l}9 \text { September } \\
2021\end{array}$ \\
\hline 25 & & COVAX-19 & $\begin{array}{c}\text { Recombinant-protein } \\
\text { based COVID-19 } \\
\text { vaccine }\end{array}$ & $\sqrt{ }$ & Finalized & $\begin{array}{l}6 \text { November } \\
2021\end{array}$ \\
\hline
\end{tabular}

* Dossier Submission dates: more than one date is possible because of the rolling submission. The dossier is accepted for submission after the screening of the received submission. ${ }^{*}$ Status of assessment: 1 . Under screening; 2. Under assessment; 3 . Waiting for responses from the applicant. 4. Risk-benefit decision 5. Final decision made. *** Predicted decision date: this is only an estimate because it depends on when all the data is submitted under rolling submission and when all the responses to the assessors' questions are submitted.

\subsection{Adenovirus-Vectored Based Vaccines}

The first trial was published in June 2020 [197]. The trial was a dose-escalation study of recombinant adenovirus type 5 vectored S. Although around $75-83 \%$ of participants recorded mild or moderate symptoms, the vaccine was determined admissible [198].

The Oxford University / AstraZeneca's adenovirus-vectored (AZD1222) vaccine was approved by the UK-Medicines and Healthcare Products Regulatory Agency [UK-MHPRA] in December 2020 and is considered as one of the most cost-effective vaccines, costing approximately $1.47-2.94 £$ per dose. AZD1222 is dependent on the chimpanzee adenovirusvectored platform (ChAdOx1/AZD1222) encoding the spike glycoprotein of SARS-CoV2. The application of the AZD1222 vaccine trial was done using two doses $\left(5.0 \times 10^{10}\right.$ and $2.2 \times 10^{10}$ ) of viral particles [199]. It was noticed that lowering the dose of viral particles had better clinical efficiency at around $90 \%$ in comparison with a $70 \%$ in the larger trial [200]. A third trial of the AZD1222 vaccine on 30,000 adults (20,000 vaccine recipients and 10,000 controls) started in August 2020 in many locations around the world. Due to the particular vulnerability of older ages against SARS-CoV-2, partly due to immunosenescence, AstraZeneca has been guiding its vaccine study and trial to clarify treatment efficacy and to measure neutralizing antibody levels (NAB) in seniors. To sum up, the side-effects were minor; AZD1222 triggered the induction of humoral responses by inducing anti-spike glycoprotein IgG nAbs, IFN $\gamma$, and T-cell responses, in most vaccines' recipients after the first dose [201,202].

Among the Jordanian population who received this vaccine, only two cases of blood clot formation were reported to this date, and most vaccine recipients suffered from mild side effects ( $\mathrm{MOH}$ report). 


\section{2. $m R N A$-Based Vaccines}

Two RNA-based vaccines were approved for use by the United States FDA emergency use authorization (EUA) in December 2020. BNT162b2 manufactured jointly by Pfizer (Kalamazoo, MI, USA) and BioNTech (Mainz, Germany) with 95\% efficiency, and mRNA-1273 manufactured by Moderna Company, Cambridge, MA, USA with $94.5 \%$ efficiency [200]. BNT162b1 is a lipid nanoparticle-formulated, nucleoside-modified mRNA encoding the receptor-binding domain of $S$ protein. Antibodies that can recognize the receptor-binding domain and neutralize SARS-CoV-2 [203]. Similarly, mRNA-1273 also coded for stabilized prefusion S [204].

In comparison with other conventional vaccines, the process of approved mRNAbased vaccines (Pfizer/BioNTech and Moderna) was unique. While conventional vaccines utilize dead forms of the virus, which are grown in cell culture, these vaccines eliminate such a time-consuming process. Instead, mRNA vaccines include a non-viral "blueprint" mRNA that encodes specific instructions for the synthesis of a non-virulent spike protein in human cells. Using a lipid nanoparticle vehicle carrier (LNP) enhances the mRNA uptake by the human cell $[205,206]$. During vaccination, the synthetic spike protein triggers the host immune response by presenting on the outer membrane of the cell to involve neutralizing antibodies, cytotoxic CD8 cells, CD4 helper cells, and memory B cells. In a later stage, when the infection with SARS-CoV-2 occurs, its natural spike protein quickly produces the host's own protective innate immune response, which had been previously sensitized by vaccination. It is important to stress the fact that mRNA did not enter into the nucleus, and no changes in cellular DNA occurred. The mRNA is degraded to a small molecule after the translation of its instructions [205].

\subsection{Whole-Virus Inactivated Vaccines}

These are conventional killed whole virus vaccines prepared in a way that had been utilized for many decades for different vaccines that are safe for breastfeeding mothers [207]. In such preparations, SARS-CoV-2 is not infectious as it is completely denatured after being grown in a cellular medium. When it is injected, the human body produces an immune response against the $S$ protein that can neutralize the virus if the infection occurs [208]. Both the Chinese and Russian vaccines Sinopharm and Sinovac, respectively, are using the inactivated whole-virus method. They are simple to manufacture and suitable for people who have compromised immune systems. Among all these types of vaccines, it is difficult to guess which is more effective at persistent protection. Moreover, such viruses are highly polymorphic, which raises concern regarding the neutralizing ability of different vaccines on continuously emerging variants (Figure 5).

\subsection{Subunit Vaccine}

This type of vaccine does not pose a risk of causing disease inside the patient's body because it does not contain live components of the virus. It contains the purified parts of the pathogen, such as proteins, or peptides, that are antigenic or necessary to form a protective immune response. This makes it safer, more stable, and suitable for people with weak immunity than other vaccines that contain the whole parts of the virus. However, the complexity of manufacturing this type of vaccine is one of the major disadvantages [209].

\subsection{Other Types}

There are other types of vaccines that are being tested by some trials, such as the multiplex plasmid DNA vaccines, the virus-like particle vaccines, and the conjugate vaccine. These available vaccines can limit the spread of the COVID-19 virus and increase immunity [209]. 


\section{The SARS-CoV-2 Variants of Concern}

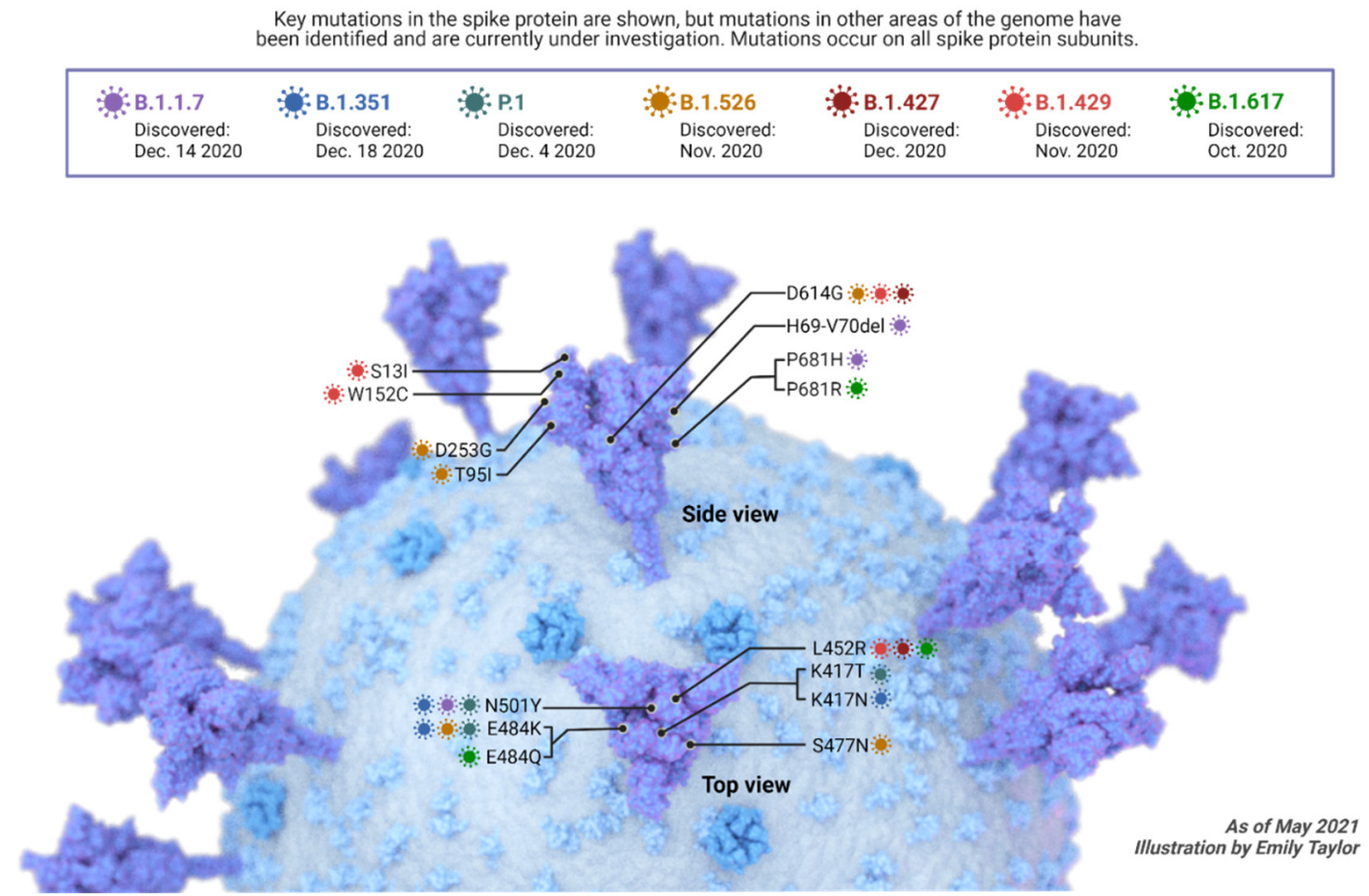

Figure 5. Common SARS-CoV-2 variants up to May 2021. (Created with BioRender.com, accessed on 10 January 2022).

\section{Discussion}

The devastating effects on global public health, global economy, and psychological well-being of humans due to the COVID-19 pandemic are still being experienced worldwide. The latest figures from the World Health Organization show more than 386 million confirmed cases and over 5 million deaths globally. As researchers and scientists, we deal with mortality figures constantly, but over 5 million deaths reported to date create an unparallel sense of responsibility [185]. Humanity was not as well-prepared to meet this pandemic as many had presumed. Nevertheless, humans are once more demonstrating extraordinary efforts in the face of adversity. The continuous and creative efforts by researchers and clinicians worldwide to find reliable treatments for COVID-19 are nothing short of acts of heroism. The development of effective vaccines against COVID-19 in such a timeframe is indeed a great achievement for all humans. At the time of the manuscript preparation, more than 983.1 million vaccine doses have been given worldwide [185]. In this review, we aimed to recognize and shed light on the latest efforts and guide future researchers towards victory in the battle against COVID-19.

Studies on several drugs demonstrated promising results. Corticosteroids, namely dexamethasone, have been supported by several large, randomized trials, and current guidance recommends the use of dexamethasone in COVID-19. The definitive role of Remdesivir as a treatment for COVID-19 is still uncertain, with several studies demonstrating efficacy and the WHO solidarity trial demonstrating no clinical benefit. The co-administration of baricitinib with Remdesivir shows potential promise. Although, the use of baricitinib in patients being treated with corticosteroids requires further research. The examined literature demonstrated that vitamin D deficiency might be associated with severe COVID-19, and several studies demonstrated conflicting results on its use as a treatment in COVID-19 patients. The potential role of chloroquine/hydroxychloroquine as a treatment has been a matter of interest to clinicians around the world. The latest evidence from several large randomized clinical trials found no benefit to mortality or other clinical aspects in hospitalized COVID-19 patients treated with chloroquine/hydroxychloroquine. Furthermore, available 
data found no clinical benefit to the use of the macrolide antibiotic azithromycin alone or with hydroxychloroquine in COVID-19. Results concerning interleukin-6 inhibitors, particularly tocilizumab, spark interest in a potential role of tocilizumab in select cases of severe COVID-19 with elevated levels of inflammatory markers. The potential role of IL-1 inhibitors (e.g., anakinra), requires further research, however. Interim results of the WHO Solidarity trial demonstrate no efficacy of interferon-beta, although smaller limited trials reported benefit.

Emerging evidence on antibody-based therapies was indeed interesting. Emerging evidence supports a potential role for early administration of high-titer convalescent plasma in high-risk individuals in the outpatient setting, and case reports on its significant efficacy in patients previously treated with rituximab reveal new populations for further research. Preliminary evidence confers optimism towards novel SARS-CoV-2-specific monoclonal antibodies such as bamlanivimab-etesevimab and casirivimab-imdevimab, but the demonstration of their effect on different variants of SARS-CoV-2 requires further research efforts. Combination use of lopinavir-ritonavir also gathered attention as potential agents in COVID-19. However, several clinical trials demonstrated no efficacy of lopinavir-ritonavir in the treatment of COVID-19 patients. Another well-known drug, colchicine, was also evaluated in the literature. Emerging data suggest no benefit in hospitalized patients, but more trials are required to fully understand the possible role of colchicine in outpatient and hospital settings.

Other potential agents are also under evaluation. With great interest, we follow trials that are being conducted on the RNA polymerase inhibitor favipiravir, which has shown promise in early trials conducted in Russia and China. The well-known antiparasitic drug ivermectin, and the HCV antivirals sofosbuvir and daclatasvir may have possible roles in COVID-19 treatment, but high-quality data from large, randomized trials is needed, to ascertain such proposed roles.

\subsection{The Role of Mathematical Models on COVID-19 Pandemic}

To study and know the approximate estimation of the transmission, mathematical model-based analysis was used, which has had an important impact on the COVID-19 pandemic. It is considered a critical tool in the battle against the SARS-COV-2 virus by facilitating a better understanding of the mechanism of disease transmission, as well as improving the resolution of cost-effectiveness of different scenarios [210]. Mathematical models of past and current epidemics have been relied on to examine the mechanism and pathogenesis of disease spread, the severity of symptoms, suspected immune response, duration to reach the appropriate immune response, time to recovery, cost, complications, and how to contain the disease [211,212]. Of these patterns: deterministic models and stochastic models, whose groups are created utilizing population data in the region or independent data with details of movement between regions. Likewise, a mechanistic model is used to study and predict the efficiency of prophylactic actions such as lockdowns and social distancing. The existing and prospective risks of COVID-19 on lifestyle behaviors can be predicted using a community-level micromodel, especially for ending the lockdown and travel restrictions. Moreover, estimation, specification, prediction models, and other models have studied and analyzed the mechanism of virus transmission [212,213]. Despite the importance of mathematical models in limiting the spread of epidemics in general, and COVID-19 in particular, many challenges to the utility of mathematical models exist. Some examples of challenges include the difficulty of translating and applying the decision based on these models or mathematical motives to limit the spread of COVID-19 or any other pandemic, as well as efforts to verify the validity of mathematical models after each pandemic to examine the reliability of these models and increase the confidence of people, governments, and institutions in these models to increase utility [213,214]. 


\subsection{Impact of COVID-19 Pandemic on Mental and Psychiatric Health and Vice Versa-A Special High-Risk Group}

During the pandemic, the World Health Organization expressed its concern regarding the mental health of people and the impact of the pandemic on them. The COVID-19 precautionary measures such as isolation and quarantine led to an increase in feelings of anxiety, depression, and insomnia, and increased opportunities for alcohol and drug abuse, contributing to self-harm and thoughts of suicide [215]. The closures that occurred around the world led to an increase in cases of domestic violence due to the increase in the estimated time that the abuser interacts with their family, and this view is supported by a survey conducted by the Indian Society of Medicine, which indicated an increase in the incidence of mental illness by $20 \%$ [216]. In Kerala, India, withdrawal symptoms appeared and suicides by alcoholics increased after the closure of venues of alcohol sales.

As we are in a battle with the SARS-CoV-2 virus, some recommendations have obsessive-compulsive disorder triggers and some excessive behaviors such as procedures related to washing hands and cleaning surfaces to reduce the spread of the disease. In addition to some emotions such as intense anxiety, fear, and phobia of meeting others or fear of isolation or death as a result of this pandemic. Or even the fear of not getting food and essential items, as some people deliberately stock up on food [48]. COVID-19 patients who suffer from mental illnesses such as Alzheimer's disease, dementia disorders, and other mental illnesses have an elevated mortality rate compared to patients who do not suffer from mental illnesses. This was shown in a meta-analysis study, where the higher mortality rate of COVID-19 patients among dementia patients was noticeable [1].

Although the diversity in the diagnosis of COVID-19 patients, age and chronic diseases were among the most important factors for predicting poor prognosis, interestingly, age and chronic diseases were also associated with dementia patients. Accordingly, dementia patients are more susceptible to diseases such as high blood pressure, diabetes, and pneumonia. If we assume the absence of the COVID-19 pandemic, the death rate due to pneumonia for dementia patients was twofold higher than people without dementia [217,218]. Another reason for the high death rate of COVID-19 in patients with dementia is the cytokine storm, where it has been shown that dementia patients have elevated proinflammatory cytokines, such as tumor necrosis factor-alpha, interleukin-1, and interleukin-6, which increases the death rate $[219,220]$. Another logical and simple reason for the high mortality of COVID-19 among dementia patients is that dementia patients may not be able to follow the advice and directions of health authorities, monitor and report symptoms of COVID-19, or even stay away from others to prevent the spread of infection [221].

Kubota $\mathrm{T}$ and Kuroda $\mathrm{N}$ conducted a systemic review on 2278 patients who had neurological diseases before the COVID-19 pandemic. They found that patients with dementia, Parkinson's disease, epilepsy, multiple sclerosis, cerebrovascular diseases, spinal cord injury, and any preexisting neurological diseases were significantly associated with severe COVID-19 symptoms, worsening of their neurological status, and increased mortality rate [222]. These findings are in complete agreement with the study by Lanza $\mathrm{G}$ et al., who found that COVID-19 can worsen the psychiatric and neurological symptoms for all people and significantly more in chronic preexisting neuropsychiatric diseases [223]. Accordingly, authorities should give more attention to these high-risk groups.

\section{Variants of Concern and Vaccines}

Vaccines are largely considered to be the most effective intervention in the battle against COVID-19. The WHO started the first vaccination program in December 2020, and more than 983.1 million vaccine doses have been given worldwide, according to the WHO [185]. According to Our World In Data [224], 493.46 million doses were given in Asia, while 266.68 million doses were given in North America and 210.11 million doses in Europe. In China alone, 235.98 million vaccine doses were given, being the highest number among countries, followed by the United States with 232.41 million doses. Relative to population, Gibraltar has given 204.07 vaccine doses per one hundred citizens, achieving $95.06 \%$ of 
fully vaccinated individuals among the population, followed by Israel with $58.63 \%$. In the middle east, the United Arab Emirates achieved 38.79\%. The United States reached 28.93\%, while the United Kingdom achieved $49.85 \%$. The latest figures show that South Africa only achieved $0.49 \%$ of fully vaccinated individuals among the population.

Like other viruses, SARS-CoV-2 evolves. Certain variants have raised global concern because of their rapid emergence within populations. The emergence of such variants raised concern regarding the neutralizing ability of currently used vaccines against such variants (Figure 5).

\subsection{B.1.1.7 Lineage (Alpha or GR/501Y.V1)}

This variant was first identified in the United Kingdom in late 2020 and was temporally associated with an increase in regional infections [225]. Several epidemiologic analyses comparing growth rates of the B.1.1.7 variant with those of other strains in the United Kingdom suggest that the B.1.1.7 variant has a transmission advantage over wild-type strains [225-227]. A report from Public Health England found a secondary infection rate of $12.9 \%$ among 37,585 contacts of individuals with the B.1.1.7 variant infection compared with $9.7 \%$ among 24,239 contacts of individuals with wild-type infection and estimated that the increase in transmissibility associated with the B.1.1.7 variant was 25-40\% [228]. In a study of nearly 55,000 individuals with B.1.1.7 infection, the risk of mortality was greater when compared with matched controls with wild-type infection (hazard ratio 1.64) [229]. However, the absolute mortality rates were low in both groups (approximately 0.4 versus 0.25 percent). In a smaller study of 496 hospitalized patients, there was no association between B.1.1.7 infection and severe disease and death, with and without adjustment for comorbidities and other potential confounders [230]. Plasma from trial participants vaccinated with BNT162b2 (Pfizer-BioNTech COVID-19 vaccine) appears to maintain neutralizing activity against B.1.1.7 [231]. Based on preliminary data, plasma from recipients of mRNA-1273 (Moderna COVID-19 vaccine) appears to maintain neutralizing activity against B.1.1.7 [232,233]. In an analysis of one of the randomized trials on ChAdOx1 nCoV-19/AZD1222 (University of Oxford, AstraZeneca, and the Serum Institute of India), efficacy against symptomatic COVID-19 causes by variant B.1.1.7 was not statistically different, when compared with other variants (70 vs. 82 percent). However, it induced lower neutralizing activity against the B.1.1.7 variant [234]. Furthermore, in a study that evaluated pseudovirus resistance to serum obtained from individuals that received two doses of inactivated-virus vaccines (BBIBP-CorV (Sinopharm) and CoronaVac (Sinovac)), B.1.1.7 showed little resistance to the neutralizing activity of vaccinee serum [235].

\subsection{B.1.351 Lineage (Beta or GH501Y.V20)}

This variant was identified in South Africa in late 2020 and spread rapidly to become the dominant variant in several South African provinces within weeks, suggesting possible increased transmissibility of this strain [236]. In a study that introduced the B.1.351 lineage spike protein into a viral construct, attenuation of neutralizing activity of convalescent plasma occurred, with 48 percent of plasma samples losing neutralizing activity [237]. Plasma from trial participants vaccinated with BNT162b2 (Pfizer-BioNTech COVID-19 vaccine) appears to maintain neutralizing activity against B.1.351, but with lower neutralizing titers (in one study, approximately two-thirds lower) than those for other circulating variants [238-240]. Plasma from recipients of mRNA-1273 (Moderna COVID-19 vaccine) appears to maintain neutralizing activity against B.1.351, but at up to six- to nine-fold lower titers than with wild-type virus [232,233]. In preliminary results of phase I/II trial in South Africa, ChAdOx1 nCoV-19/AZD1222 (University of Oxford, AstraZeneca, and the Serum Institute of India) did not reduce the rate of mild to moderate COVID-19 over a timeframe when B.1.351 was the dominant circulating variant, but the trial was small, and the number of cases was low, and the estimate of vaccine efficacy had wide confidence intervals (21.9 percent, 95\% CI - 49.9 to 59.8) [241]. Furthermore, in phase, I/II placebo-controlled randomized trials of healthy individuals 18 to 80 years old who received two doses of 
BBIBP-CorV (Sinopharm), all recipients of two vaccine doses developed neutralizing and binding antibodies against SARS-CoV-2 but demonstrated the same trend observed with other vaccines, where neutralizing activity against the B.1.351 was reduced [235]. Overall, vaccines remain effective against the B.1.351 lineage.

\subsection{B.1.1.28 Lineage // [Lineage P.1 (B.1.1.28.1) (Gamma); Lineage P.2 (B.1.1.28.2) Zeta; P.7]}

The expert estimations revealed that P.2 lineage (B.1.1.28.2 or Zeta) started in February 2020 and the first detection was in November in Rio de Janeiro. However, P.2 spread rapidly to arrive at its peak at the end of 2020. While P.1 (B.1.1.28.1 or gamma) emerged in August 2020 and the first detection was in December 2020 in Amazonas state. There was also evidence about P.7 that originated in south Brazil then spread rapidly to northern Brazil. These three lineages of B.1.1.28 (especially P.1 and P.2) co-dominated and made the second wave in Brazil [242].

In general, B.1.1.28 lineage contains 10 spikes mutations and shares the same three mutations in the receptor-binding domain (RBD) that found in the beta variant also [243]. A previous COVID-19 infection cannot be adequate to protect the population from this variant [244]. Although a relative resistance of SARS-CoV-2 variants B.1.1.7 and B.1.351 was reported to monoclonal antibodies, they are not similar to the B.1.1.28 lineage, which was resistant to monoclonal antibodies, convalescent plasma therapy, and vaccine sera [243]. Plasma from an 83-year-old man who was vaccinated with BNT162b2 (Pfizer-BioNTech COVID-19 vaccine) and diagnosed with B.1.1.28.1 (P1 lineage), developed mild COVID-19 symptoms that persist for two days only. Although the Pfizer-BioNTech COVID-19 vaccine provoked an immune response that attenuated the severity of the disease among those elderly patients from severe symptoms in non-vaccinated patients to mild symptoms in this vaccinated patient, there was a reduction of the vaccine efficacy against this Brazilian variant [245]. In a study that included 9433 participants who had two doses of ChAdOx1 nCoV-19/AZD1222 vaccine (University of Oxford, AstraZeneca, and the Serum Institute of India), the efficacy of the vaccine on the B.1.1.28 lineage was 73\%, and this vaccine had $95 \%$ protection rate from COVID-19 hospitalization [246].

\subsection{B.1.617.2 (Delta Variant)}

The B.1.617.2 (delta) variant was first detected in India in December 2020 and became the most reported variant in the country starting in April 2021 then rapidly spread and dominated across the world. It has 10 mutations in the spike protein [247]. In a study that enrolled 156 participants who received one or two doses of BNT162b2 (Pfizer-BioNTech COVID-19 vaccine) or AZD1222 (University of Oxford, AstraZeneca) vaccines. They found that the B.1.617.2 (delta) variant had a reduction in the neutralization titer by 11.3-fold after two doses of Pfizer-BioNTech vaccine, while the reduction was 7.77 and 9.56-fold in B.1.617.1 (Kappa) and B.1.351 (beta) variant respectively. The reduction after two doses of AstraZeneca was 4.01-fold in beta, 1.48-fold in beta, and 0.69 in Kappa variant [248]. Lopez Bernal et al. reported that the efficacy of BNT162b2 (Pfizer-BioNTech COVID-19 vaccine) on delta variant was $35.6 \%$ for one dose and $88.0 \%$ for the two doses. At the same time, the efficacy of AZD1222 (University of Oxford, AstraZeneca, Oxford, UK) was 30.0\% for one dose and $67.0 \%$ for the two doses [249]. Although two doses of Pfizer-BioNTech had provoked significantly higher antibody titers than two doses of AstraZeneca, both vaccines had a highly effective level for delta variant after two doses [248,249]. Thus, we recommend two doses of vaccines to provoke the maximum immunity of the vaccine, and there may be a need for a booster dose of vaccines over time to protect from the coming variants.

\subsection{B.1.1.529 (Omicron)}

This variant was first identified and confirmed in Botswana, South Africa, on 9 November 2021. Then it was reported to the WHO on 24 November 2021 [250]. Tulio de Oliveira and his team, who identified this variant, reported that these new mutations in the COVID- 
19 virus were originated in HIV patients who had the virus for weeks or months [251]. Omicron had 32 mutations in spike protein which help it to be more infectious, at faster rates than other variants' waves, and may be able to escape from vaccines antibodies [250252]. It is estimated to be 10-fold more infectious than the original virus [253]. Now, it has reached many countries and is still spread rapidly. Accordingly, the WHO and many countries had protective guidelines to limit the spread of this variant by travel restriction toward and from South Africa, or obligatory quarantine for new arrivals, and testing PCR before and after their travels.

There are no specific symptoms associated with infection by the Omicron variant [254]. Notwithstanding, the Omicron variant has a higher prevalence of asymptomatic patients with high nasopharyngeal viral RNA in comparison to other variants. This may be the major contributory factor for the high and rapid spreading of Omicron worldwide among all populations, even those with a prior COVID-19 infection [255]. However, there was a decrease in severe symptoms or hospitalization rate caused by Omicron variants [256,257]. Still, the rapid spread of this variant could contribute to a cumulative high number of admissions to the hospitals. Omicron may have the ability to evade the available vaccines and has demonstrated reduced vaccine efficacy by twofold more than the Delta variant [253]. However, despite that reduction of vaccine efficacy, the currently available vaccines can protect the population from severe Omicron infection [258].

The infection with the Omicron variant can boost and enhance more immune responses than other variants [254]. This means that having a previous natural infection or having the booster dose of vaccines was associated with partial protection against severe Omicron variant symptoms and hospital admissions [257,259-261]. A previous COVID-19 infection and having two doses of vaccines can decrease the risk of hospital admission by $50 \%$ and 41\%, respectively [261]. Having two doses of BNT162b2 (Pfizer-BioNTech COVID-19 vaccine) can provide $33 \%$ protection against Omicron variant infection while $80 \%$ against Delta variant infection. Additionally, it can decrease severe COVID-19 symptoms that require hospitalization by $70 \%$ and $93 \%$ against Omicron and Delta variants, respectively [256]. Moreover, the immunity gained by previous COVID-19 infection was found to be less effective against the Omicron variant compared with Delta and Beta variants [256]. This means that Omicron has more ability to reinfect people who have previous COVID-19 infections.

Some subvariants resulted from Omicron and started to spread in a limited way compared to Omicron. Deltacron, BA.2, and IHU variants, which were recently identified in Cyprus, Denmark, and France, respectively, were considered as subvariants from Omicron with not enough available scientific data about them. However, the WHO only considered the omicron variant as a variant of concern (VOC). The early preliminary data predicts that the available vaccines with boosting dose may protect the patients of these subvariants from severe COVID-19 symptoms and hospitalization.

\section{Is the Booster Dose Useful or Not?}

Omicron showed a significant reduction in vaccines-induced neutralizing antibodies for most of the available vaccines (e.g., BNT162b2 (Pfizer-BioNTech COVID-19 vaccine), mRNA-1273 (Moderna vaccine), Ad26.COV2.S (Janssen/Johnson \& Johnson vaccine), Sputnik, and Sinopharm) [261]. The effectiveness of two doses of AZD1222 (the Oxford University / AstraZeneca) reduced from $44 \%$ against the Delta variant to 5\% against the Omicron variant. Similarly, the effectiveness of two doses of BNT162b2 (Pfizer-BioNTech vaccine) reduces from $70 \%$ to $19 \%$ against Delta and Omicron variants, respectively [261]. However, after giving the booster dose of one of the mRNA-based vaccines (Pfizer/BioNTech or Moderna), the effectiveness raised from $5 \%$ to $73 \%$ in people who had previously two doses of AZD1222 (the Oxford University/AstraZeneca) and raised from 19\% to 77\% in people who had previously two doses of BNT162b2 (Pfizer-BioNTech vaccine) [261]. Likewise, Hoffmann M. et al. found that although the Omicron variant has 12 to 44 -fold more resistant to BNT162b2 (Pfizer-BioNTech COVID-19 vaccine) than the Delta variant, having 
either a booster dose of BNT162b2 (Pfizer-BioNTech COVID-19 vaccine) or having two heterologous doses from BNT162b2 (Pfizer-BioNTech COVID-19 vaccine) and ChAdOx1 (Astra Zeneca-Oxford) were found to be more efficient in producing noticeable neutralizing antibodies that can protect against the Omicron variant [262].

Accorsi EK et al. conducted a large case-control study to evaluate the effectiveness of mRNA-based vaccines (Pfizer/BioNTech or Moderna) on Omicron and Delta variants. They divided their samples' vaccination status into those who were vaccinated with third dose (booster dose) after at least six months from the second dose, those who were vaccinated with only two doses before at least six months (who didn't have the booster dose although they were eligible for it), and those who were not vaccinated. They included 23,391 American adults as a case group (56.0\% of them have been infected with Omicron variant and the rest with Delta variant) and 46,764 as a control group. They found that receiving three doses of mRNA-based vaccines (either Pfizer/BioNTech or Moderna) was associated with a higher protection rate against Delta and Omicron variants compared with receiving only two doses of vaccines or being unvaccinated. Pfizer/BioNTech and Moderna vaccines showed more protection rate against the Delta variant compared with the Omicron variant [263].

Garcia-Beltran WF et al. found that most vaccines (which was Pfizer/BioNTech, Moderna, or Johnson \& Johnson in their study) were unable to produce detectable neutralization against Omicron variant unless boosted with either one of mRNA-based vaccines (Pfizer/BioNTech or Moderna). They found that three doses of any mRNA-based vaccines (Pfizer/BioNTech or Moderna) were significantly associated with good neutralization against Omicron and Delta variants. Moreover, adenovirus vectored vaccine (Ad26.COV2.S vaccines which is Janssen/Johnson \& Johnson vaccine) was significantly associated with higher neutralization against Omicron and Delta variants if boosted with mRNA-1273 (Moderna vaccine) rather than boosted with Ad26.COV2.S vaccine alone [264].

Costa Clemens SA et al. conducted their study on 1240 Brazilian adults who had two doses of Sinovac vaccine before six months. They divided the participants into four groups where they received a third (booster) dose, either homologous dose of Sinovac vaccine or heterologous dose from BNT162b2 (Pfizer-BioNTech COVID-19 vaccine, which is mRNA based-vaccine), Ad26.COV2.S vaccine (aka Janssen/Johnson \& Johnson vaccine, which is adenovirus vectored vaccine), or AZD1222 vaccine (aka Astra Zeneca-Oxford, which is recombinant adenoviral-vectored ChAdOx1 nCoV-19 vaccine). They found that the neutralizing antibodies before taking any booster dose were $20.4 \%$ and $8.9 \%$ among participants aged 18-60 years and older than 60 years, respectively, after six months of taking two doses of Sinovac vaccine. However, there was a significant increase in neutralizing antibodies against Delta and Omicron variants after 28 days from taking the booster dose for all types.

Moreover, a heterologous booster dose can enhance more potent protection and neutralizing antibodies compared with a homologous booster dose [265]. This agrees with the results of Pérez-Then E, et al., who found that having a heterologous booster dose of BNT162b2 (Pfizer-BioNTech COVID-19 vaccine) for participants who had primary two doses of Sinovac vaccine, can cause increased neutralizing antibodies against Delta variant to be similar to those who received two doses of BNT162b2 vaccines and can increase the antibodies by 1.4-fold against Omicron variant compared to two doses of BNT162b2 vaccines [266].

In the COV-BOOST study, which was a large, blinded, multicenter randomized, control trial conducted in the United Kingdom, seven vaccines were given as a third booster dose for 2878 adult participants aged more than 30 years and primarily received two doses of BNT162b2 (Pfizer-BioNTech COVID-19 vaccine) or ChAdOx1 nCoV-19 (Astra ZenecaOxford vaccine). They used seven booster dose vaccines, one of the following: BNT162b2 (Pfizer-BioNTech), a half dose of BNT162b2 (Pfizer-BioNTech), mRNA-1273 (Moderna vaccine), Ad26.COV2.S vaccine (Janssen/Johnson \& Johnson vaccine), Novavax, a half dose of Novavax, or ChAdOx1 nCoV-19 (Astra Zeneca-Oxford vaccine). Although there 
were some differences in neutralizing antibodies produced by the booster dose, all vaccines showed good immunological response with no threat to the participants' safety. Moreover, the best immunogenicity was with a booster dose of Moderna, then Pfizer-BioNTech, then half dose of Pfizer-BioNTech, then the rest of vaccines for both who primary received two doses of Astra Zeneca-Oxford or Pfizer-BioNTech vaccines. The highest immune response was among participants who received two primary doses of Pfizer-BioNTech followed by Moderna booster dose [267].

On the other hand, Singhal T stated that giving booster doses of vaccines can disrupt the global equity in vaccines distributions among the countries with no marked impact on controlling the rapid spread of the Omicron variant [260].

\section{Conclusions}

COVID-19 became the most significant battle in health care in recent history and required sufficient global coordination and response to address. Vast efforts were conducted to produce efficient vaccines and treatments. Consequently, there is progress in the reduction of morbidity and mortality rates. However, the continuous appearance of SARS-CoV2 variants is a major challenge worldwide. Therefore, further efforts are recommended to be taken. All eligible people have at least the full doses of the available vaccine in their country. The WHO and the global committees should make more efforts to distribute vaccines for all countries in the world, especially low-income countries. This can lead to controlling and decreasing the number of COVID-19 patients, severity of infection, and mortality, in addition to decreasing the hot spots country from generating new resistant variants. Moreover, we recommend using heterologous vaccines - if available - with different mechanisms of action.

We strongly encourage taking a booster dose every six months from the date of the last vaccine with a preferable choice of using a heterologous dose, especially one of the mRNA-based vaccines (Pfizer/BioNTech or Moderna). This is because using a strategy based on a heterologous vaccine can increase immunogenicity and neutralize antibodies against mutated SARS-CoV-2 variants. More efforts are required for continuous testing and evaluating the effectiveness of the currently available vaccines on any new SARS-CoV-2 variant. Consequently, the international authorities should urgently report any emergent or suspected mutation to the WHO. In addition to the rapid investigations, research, and data collection and make them available for the public, investigators, and researchers. Finally, hand hygiene, well-fitting masks, physical distancing, avoiding full and crowded places are the simple requirements for everyone to minimize the risk of infection of any variants and its complications.

Author Contributions: Conceptualization, A.K., J.B.-I., M.S.A.Z. and E.H.; methodology, A.K., J.B.-I., K.A.-S., M.S.A.Z. and E.H.; software, A.K., J.B.-I., T.Q., M.I.A., S.A.A., K.A.-S., M.M.T. and F.E.H.; validation, M.S.A.Z., E.H., I.H.B., M.A.-S. and C.T.C.; investigation, A.K. and M.S.A.Z.; data curation, A.K., J.B.-I., K.A.-S., E.H. and M.S.A.Z.; writing—original draft preparation, A.K., J.B.-I., T.Q., M.I.A., S.A.A., K.A.-S., M.M.T. and F.E.H.; writing—review and editing, A.K., M.S.A.Z., E.H., I.H.B., M.A.-S. and C.T.C.; visualization, M.S.A.Z., E.H., I.H.B., M.A.-S. and C.T.C.; supervision, M.S.A.Z.; project administration, M.S.A.Z. Both A.K. and J.B.-I. contributed equally to this manuscript. All authors have read and agreed to the published version of the manuscript.

Funding: This research received no external funding.

Institutional Review Board Statement: Not applicable.

Informed Consent Statement: Not applicable.

Data Availability Statement: Not applicable.

Acknowledgments: We are very thankful to the BioRener application for the given license of templets used in this review according to the user plan Murtaza Tambuwala, Ulster University).

Conflicts of Interest: The authors declare no conflict of interest. 


\section{References}

1. Liu, N.; Sun, J.; Wang, X.; Zhao, M.; Huang, Q.; Li, H. The Impact of Dementia on the Clinical Outcome of COVID-19: A Systematic Review and Meta-Analysis. J. Alzheimers. Dis. 2020, 78, 1775-1782. [CrossRef]

2. Rabi, F.A.; Al Zoubi, M.S.; Kasasbeh, G.A.; Salameh, D.M.; Al-Nasser, A.D. SARS-CoV-2 and coronavirus disease 2019: What we know so far. Pathogens 2020, 9, 231. [CrossRef]

3. Song, Z.; Xu, Y.; Bao, L.; Zhang, L.; Yu, P.; Qu, Y.; Zhu, H.; Zhao, W.; Han, Y.; Qin, C. From SARS to MERS, thrusting coronaviruses into the spotlight. Viruses 2019, 11, 59. [CrossRef]

4. Graham, R.L.; Donaldson, E.F.; Baric, R.S. A decade after SARS: Strategies for controlling emerging coronaviruses. Nat. Rev. Microbiol. 2013, 11, 836-848. [CrossRef] [PubMed]

5. Aljabali, A.A.; Alzoubi, L.; Hamzat, Y.; Alqudah, A.; Obeid, M.A.; Al Zoubi, M.S.; Ennab, R.M.; Alshaer, W.; Albatayneh, K.; Al-Trad, B.; et al. A Potential Mri Agent and an Anticancer Drug Encapsulated within Cpmv Virus-Like Particles. Comb Chem High Throughput Screen 2021, 24, 1557-1571. [CrossRef] [PubMed]

6. Woo, P.C.Y.; Huang, Y.; Lau, S.K.P.; Yuen, K.-Y. Coronavirus Genomics and Bioinformatics Analysis. Viruses 2010, 2, 1804-1820. [CrossRef] [PubMed]

7. Hosseini, E.S.; Kashani, N.R.; Nikzad, H.; Azadbakht, J.; Bafrani, H.H.; Kashani, H.H. The novel coronavirus Disease-2019 (COVID-19): Mechanism of action, detection and recent therapeutic strategies. Virology 2020, 551, 1-9. [CrossRef]

8. Wiersinga, W.J.; Rhodes, A.; Cheng, A.C.; Peacock, S.J.; Prescott, H.C. Pathophysiology, transmission, diagnosis, and treatment of coronavirus disease 2019 (COVID-19): A review. JAMA 2020, 324, 782-793. [CrossRef] [PubMed]

9. WHO Rapid Evidence Appraisal for COVID-19 Therapies (REACT) Working Group; Sterne, J.A.C.; Murthy, S.; Diaz, J.V.; Slutsky, A.S.; Villar, J.; Angus, D.C.; Annane, D.; Azevedo, L.C.P.; Berwanger, O.; et al. Association Between Administration of Systemic Corticosteroids and Mortality Among Critically Ill Patients With COVID-19: A. Meta-analysis. JAMA 2020, 324, $1330-1341$. [PubMed]

10. Wu, Z.; McGoogan, J.M. Characteristics of and Important Lessons from the Coronavirus Disease 2019 (COVID-19) Outbreak in China: Summary of a Report of 72314 Cases from the Chinese Center for Disease Control and Prevention. JAMA 2020, 323, 1239-1242. [CrossRef] [PubMed]

11. Tang, N.L.-S.; Chan, P.K.-S.; Wong, C.-K.; To, K.-F.; Wu, A.K.-L.; Sung, Y.-M.; Hui, D.S.-C.; Sung, J.J.-Y.; Lam, C.W.-K. Early enhanced expression of interferon-inducible protein-10 (CXCL-10) and other chemokines predicts adverse outcome in severe acute respiratory syndrome. Clin. Chem. 2005, 51, 2333-2340. [CrossRef] [PubMed]

12. Qian, Z.; Travanty, E.A.; Oko, L.; Edeen, K.; Berglund, A.; Wang, J.; Ito, Y.; Holmes, K.V.; Mason, R.J. Innate immune response of human alveolar type II cells infected with severe acute respiratory syndrome-coronavirus. Am. J. Respir. Cell Mol. Biol. 2013, 48, 742-748. [CrossRef] [PubMed]

13. Muratori, P.; Lenzi, M.; Muratori, L.; Granito, A. Antinuclear antibodies in COVID 19. Clin. Transl. Sci. 2021, 14, 1627-1628. [CrossRef] [PubMed]

14. Wilson, K.C.; Chotirmall, S.H.; Bai, C.; Rello, J. COVID-19: Interim guidance on management pending empirical evidence. Am. Thorac. Soc.-Led Int. Task Force 2020, 12. Available online: https://www.thoracic.org/COVID/COVID-19-guidance.pdf (accessed on 10 January 2022).

15. Alhazzani, W.; Møller, M.H.; Arabi, Y.M.; Loeb, M.; Gong, M.N.; Fan, E.; Oczkowski, S.; Levy, M.M.; Derde, L.; Dzierba, A.; et al. Surviving Sepsis Campaign: Guidelines on the management of critically ill adults with Coronavirus Disease 2019 (COVID-19). Intensive Care Med. 2020, 46, 854-887. [CrossRef]

16. NIH. Coronavirus Disease 2019 (COVID-19) Treatment Guidelines; National Institutes of Health: Bethesda, MD, USA, 2020.

17. Tobin, M.J. Basing Respiratory Management of COVID-19 on Physiological Principles; American Thoracic Society: New York, NY, USA, 2020.

18. Bleibtreu, A.; Jaureguiberry, S.; Houhou, N.; Boutolleau, D.; Guillot, H.; Vallois, D.; Lucet, J.C.; Robert, J.; Mourvillier, B.; Delemazure, J.; et al. Clinical management of respiratory syndrome in patients hospitalized for suspected Middle East respiratory syndrome coronavirus infection in the Paris area from 2013 to 2016. BMC Infect. Dis. 2018, 18, 1-9. [CrossRef]

19. Sheahan, T.P.; Sims, A.C.; Leist, S.R.; Schäfer, A.; Won, J.; Brown, A.J.; Montgomery, S.A.; Hogg, A.; Babusis, D.; Clarke, M.O.; et al. Comparative therapeutic efficacy of remdesivir and combination lopinavir, ritonavir, and interferon beta against MERS-CoV. Nat. Commun. 2020, 11, 222. [CrossRef]

20. Huang, C.; Wang, Y.; Li, X.; Ren, L.; Zhao, J.; Hu, Y.; Zhang, L.; Fan, G.; Xu, J.; Gu, X.; et al. Clinical features of patients infected with 2019 novel coronavirus in Wuhan, China. Lancet 2020, 395, 497-506. [CrossRef]

21. Savarino, A.; Di Trani, L.; Donatelli, I.; Cauda, R.; Cassone, A. New insights into the antiviral effects of chloroquine. Lancet Infect. Dis. 2006, 6, 67-69. [CrossRef]

22. Touret, F.; de Lamballerie, X. Of chloroquine and COVID-19. Antivir. Res. 2020, 177, 104762. [CrossRef]

23. Yan, Y.; Zou, Z.; Sun, Y.; Li, X.; Xu, K.-F.; Wei, Y.; Jin, N.; Jiang, C. Anti-malaria drug chloroquine is highly effective in treating avian influenza A H5N1 virus infection in an animal model. Cell Res. 2013, 23, 300-302. [CrossRef]

24. Inglot, A.D. Comparison of the antiviral activity in vitro of some non-steroidal anti-inflammatory drugs. J. Gen. Virol. 1969, 4, 203-214. [CrossRef] [PubMed]

25. Miller, D.K.; Lenard, J. Antihistaminics, local anesthetics, and other amines as antiviral agents. Proc. Natl. Acad. Sci. USA 1981, 78 , 3605-3609. [CrossRef] [PubMed] 
26. Keyaerts, E.; Vijgen, L.; Maes, P.; Neyts, J.; Van Ranst, M. In vitro inhibition of severe acute respiratory syndrome coronavirus by chloroquine. Biochem. Biophys. Res. Commun. 2004, 323, 264-268. [CrossRef]

27. Chauhan, A.; Tikoo, A. The enigma of the clandestine association between chloroquine and HIV-1 infection. HIV Med. 2015, 16, 585-590. [CrossRef] [PubMed]

28. Helal, G.K.; Gad, M.A.; Abd-Ellah, M.F.; Eid, M.S. Hydroxychloroquine augments early virological response to pegylated interferon plus ribavirin in genotype-4 chronic hepatitis C patients. J. Med. Virol. 2016, 88, 2170-2178. [CrossRef] [PubMed]

29. Vincent, M.J.; Bergeron, E.; Benjannet, S.; Erickson, B.R.; Rollin, P.E.; Ksiazek, T.G.; Seidah, N.G.; Nichol, S.T. Chloroquine is a potent inhibitor of SARS coronavirus infection and spread. Virol. J. 2005, 2, 69. [CrossRef] [PubMed]

30. Sanders, J.M.; Monogue, M.L.; Jodlowski, T.Z.; Cutrell, J.B. Pharmacologic treatments for coronavirus disease 2019 (COVID-19): A review. JAMA 2020, 323, 1824-1836. [CrossRef]

31. Wang, M.; Cao, R.; Zhang, L.; Yang, X.; Liu, J.; Xu, M.; Shi, Z.; Hu, Z.; Zhong, W.; Xiao, G. Remdesivir and chloroquine effectively inhibit the recently emerged novel coronavirus (2019-nCoV) in vitro. Cell Res. 2020, 30, 269-271. [CrossRef]

32. RECOVERY Collaborative Group; Horby, P.; Mafham, M.; Linsell, L.; Bell, J.L.; Staplin, N.; Emberson, J.R.; Wiselka, M.; Ustianowski, A.; Elmahi, E.; et al. Effect of Hydroxychloroquine in Hospitalized Patients with COVID-19. N. Engl. J. Med. 2020, 383, 2030-2040.

33. Tang, W.; Cao, Z.; Han, M.; Wang, Z.; Chen, J.; Sun, W.; Wu, Y.; Xiao, W.; Liu, S.; Chen, E.; et al. Shengyong Liu, and Erzhen Chen. Hydroxychloroquine in patients with mainly mild to moderate coronavirus disease 2019: Open label, randomised controlled trial. BMJ 2020, 369, m1849. [CrossRef]

34. Magagnoli, J.; Narendran, S.; Pereira, F.; Cummings, T.H.; Hardin, J.W.; Sutton, S.S.; Ambati, J. Outcomes of hydroxychloroquine usage in United States veterans hospitalized with COVID-19. MedRxiv 2020, 1, 114-127.e3. [CrossRef] [PubMed]

35. Cavalcanti, A.B.; Zampieri, F.G.; Rosa, R.G.; Azevedo, L.C.; Veiga, V.C.; Avezum, A.; Damiani, L.P.; Marcadenti, A.; KawanoDourado, L.; Lisboa, T.; et al. Hydroxychloroquine with or without Azithromycin in Mild-to-Moderate COVID-19. N. Engl. J. Med. 2020, 383, 2041-2052. [CrossRef] [PubMed]

36. Self, W.H.; Semler, M.W.; Leither, L.M.; Casey, J.D.; Angus, D.C.; Brower, R.G.; Chang, S.Y.; Collins, S.P.; Eppensteiner, J.C.; Filbin, M.R.; et al. Effect of Hydroxychloroquine on Clinical Status at 14 Days in Hospitalized Patients with COVID-19: A Randomized Clinical Trial. JAMA 2020, 324, 2165-2176. [CrossRef] [PubMed]

37. Food and Drug Administration (FDA). Coronavirus (COVID-19) Update: FDA Revokes Emergency Use Authorization for Chloroquine and Hydroxychloroquine. 2020. Available online: https:/ /www.fda.gov/news-events/press-announcements/ coronavirus-COVID-19-update-fda-revokes-emergency-use-authorization-chloroquine-and (accessed on 24 April 2021).

38. Singh, A.K.; Singh, A.; Singh, R.; Misra, A. Remdesivir in COVID-19: A critical review of pharmacology, pre-clinical and clinical studies. Diabetes Metab. Syndr. Clin. Res. Rev. 2020, 14, 641-648. [CrossRef] [PubMed]

39. Ferner, R.E.; Aronson, J.K. Remdesivir in COVID-19. BMJ 2020, 369, m1610. [CrossRef] [PubMed]

40. Singhal, T. A review of coronavirus disease-2019 (COVID-19). Indian J. Pediatrics 2020, 87, 281-286. [CrossRef]

41. Spinner, C.D.; Gottlieb, R.L.; Criner, G.J.; Arribas López, J.R.; Cattelan, A.M.; Soriano Viladomiu, A.; Ogbuagu, O.; Malhotra, P.; Mullane, K.M.; Castagna, A.; et al. Effect of remdesivir vs standard care on clinical status at 11 days in patients with moderate COVID-19: A randomized clinical trial. JAMA 2020, 324, 1048-1057. [CrossRef]

42. Goldman, J.D.; Lye, D.C.; Hui, D.S.; Marks, K.M.; Bruno, R.; Montejano, R.; Spinner, C.D.; Galli, M.; Ahn, M.-Y.; Nahass, R.G.; et al. Remdesivir for 5 or 10 days in patients with severe COVID-19. N. Engl. J. Med. 2020, 383, 1827-1837. [CrossRef]

43. Pizzorno, A.; Padey, B.; Dubois, J.; Julien, T.; Traversier, A.; Dulière, V.; Brun, P.; Lina, B.; Rosa-Calatrava, M.; Terrier, O. In vitro evaluation of antiviral activity of single and combined repurposable drugs against SARS-CoV-2. Antivir. Res. 2020, 181, 104878. [CrossRef]

44. Sheahan, T.P.; Sims, A.C.; Graham, R.L.; Menachery, V.D.; Gralinski, L.E.; Case, J.B.; Leist, S.R.; Pyrc, K.; Feng, J.Y.; Trantcheva, I.; et al. Broad-spectrum antiviral GS-5734 inhibits both epidemic and zoonotic coronaviruses. Sci. Transl. Med. 2017, 9, eaal3653. [CrossRef]

45. Brown, A.J.; Won, J.J.; Graham, R.L.; Dinnon, K.H.; Sims, A.C.; Feng, J.Y.; Cihlar, T.; Denison, M.R.; Baric, R.S.; Sheahan, T.P. Broad spectrum antiviral remdesivir inhibits human endemic and zoonotic deltacoronaviruses with a highly divergent RNA dependent RNA polymerase. Antivir. Res. 2019, 169, 104541. [CrossRef] [PubMed]

46. De Wit, E.; Feldmann, F.; Cronin, J.; Jordan, R.; Okumura, A.; Thomas, T.; Scott, D.; Cihlar, T.; Feldmann, H. Prophylactic and therapeutic remdesivir (GS-5734) treatment in the rhesus macaque model of MERS-CoV infection. Proc. Natl. Acad. Sci. USA 2020, 117, 6771-6776. [CrossRef]

47. Beigel, J.H.; Tomashek, K.M.; Dodd, L.E.; Mehta, A.K.; Zingman, B.S.; Kalil, A.C.; Hohmann, E.; Chu, H.Y.; Luetkemeyer, A.; Kline, S.; et al. Remdesivir for the Treatment of COVID-19-Final Report. N. Engl. J. Med. 2020, 383, 1813-1826. [CrossRef] [PubMed]

48. Pan, H.; Peto, R.; Henao-Restrepo, A.M.; Preziosi, M.P.; Sathiyamoorthy, V.; Abdool Karim, Q.; Alejandria, M.M.; Hernández García, C.; Kieny, M.P.; Malekzadeh, R.; et al. Repurposed Antiviral Drugs for COVID-19-Interim Who Solidarity Trial Results. N. Engl. J. Med. 2021, 384, 497-511. [PubMed]

49. Wang, Y.; Zhang, D.; Du, G.; Du, R.; Zhao, J.; Jin, Y.; Fu, S.; Gao, L.; Cheng, Z.; Lu, Q.; et al. Remdesivir in adults with severe COVID-19: A randomised, double-blind, placebo-controlled, multicentre trial. Lancet 2020, 395, 1569-1578. [CrossRef] 
50. Jorgensen, S.C.J.; Tse, C.L.Y.; Burry, L.; Dresser, L.D. Baricitinib: A Review of Pharmacology, Safety, and Emerging Clinical Experience in COVID-19. Pharmacotherapy 2020, 40, 843-856. [CrossRef] [PubMed]

51. Fact Sheet for Healthcare Providers: Emergency Use Authorization (EUA) of Baricitinib. 2020. Available online: http:/ / pi.lilly. com/eua/baricitinib-eua-factsheet-hcp.pdf (accessed on 26 April 2021).

52. Kalil, A.C.; Patterson, T.F.; Mehta, A.K.; Tomashek, K.M.; Wolfe, C.R.; Ghazaryan, V.; Marconi, V.C.; Ruiz-Palacios, G.M.; Hsieh, L.; Kline, S.; et al. Baricitinib plus Remdesivir for Hospitalized Adults with COVID-19. N. Engl. J. Med. 2021, 384, 795-807. [CrossRef] [PubMed]

53. Gómez, R.I.; Méndez, R.; Palanques-Pastor, T.; Ballesta-López, O.; Almenar, C.B.; Vericat, J.E.M.; López-Briz, E.; Font-Noguera, I.; Villanueva, R.M.; Iborra, J.A.R.; et al. Baricitinib against severe COVID-19: Effectiveness and safety in hospitalised pretreated patients. Eur. J. Hosp. Pharm. 2021. ejhpharm-2021-002741. [CrossRef]

54. Nussey, S.; Whitehead, S. Endocrinology: An Integrated Approach; BIOS Scientific Publishers: Milton Park, UK, 2001.

55. Arabi, Y.M.; Mandourah, Y.; Al-Hameed, F.; Sindi, A.A.; Almekhlafi, G.A.; Hussein, M.A.; Jose, J.; Pinto, R.; Al-Omari, A.; Kharaba, A.; et al. Corticosteroid therapy for critically ill patients with Middle East respiratory syndrome. Am. J. Respir. Crit. Care Med. 2018, 197, 757-767. [CrossRef]

56. Stockman, L.J.; Bellamy, R.; Garner, P. SARS: Systematic review of treatment effects. PLoS Med. 2006, 3, e343. [CrossRef]

57. World Health Organization. Clinical Management of Severe Acute Respiratory Infection (SARI) When COVID-19 Disease is Suspected: Interim guidance, 13 March 2020; World Health Organization: Geneva, Switzerland, 2020.

58. Fortuno, C.; James, P.A.; Spurdle, A.B. Current review of TP53 pathogenic germline variants in breast cancer patients outside Li-Fraumeni syndrome. Hum. Mutat. 2018, 39, 1764-1773. [CrossRef] [PubMed]

59. Meric-Bernstam, F.; Zheng, X.; Shariati, M.; Damodaran, S.; Wathoo, C.; Brusco, L.; Demirhan, M.E.; Tapia, C.; Eterovic, A.K.; Basho, R.K.; et al. Survival Outcomes by TP53 Mutation Status in Metastatic Breast Cancer. JCO Precis. Oncol. 2018, $2018,1-15$. [CrossRef]

60. Williams, L.A.; Butler, E.N.; Sun, X.; Allott, E.H.; Cohen, S.M.; Fuller, A.M.; Hoadley, K.A.; Perou, C.M.; Geradts, J.; Olshan, A.F.; et al. TP53 protein levels, RNA-based pathway assessment, and race among invasive breast cancer cases. NPJ Breast Cancer 2018, 4, 13. [CrossRef] [PubMed]

61. Huszno, J.; Grzybowska, E. TP53 mutations and SNPs as prognostic and predictive factors in patients with breast cancer. Oncol. Lett. 2018, 16, 34-40. [CrossRef] [PubMed]

62. Rochwerg, B.; Siemieniuk, R.A.; Agoritsas, T.; Lamontagne, F.; Askie, L.; Lytvyn, L.; Agarwal, A.; Leo, Y.-S.; Macdonald, H.; Zeng, L.; et al. A living WHO guideline on drugs for COVID-19. BMJ 2020, 370, m3379.

63. Wu, C.; Chen, X.; Cai, Y.; Xia, J.; Zhou, X.; Xu, S.; Huang, H.; Zhang, L.; Zhou, X.; Du, C.; et al. Risk Factors Associated with Acute Respiratory Distress Syndrome and Death in Patients with Coronavirus Disease 2019 Pneumonia in Wuhan, China. JAMA Intern. Med. 2020, 180, 934-943. [CrossRef]

64. Siemieniuk, R.A.; Bartoszko, J.J.; Ge, L.; Zeraatkar, D.; Izcovich, A.; Kum, E.; Pardo-Hernandez, H.; Qasim, A.; Martinez, J.P.D.; Rochwerg, B.; et al. Drug treatments for COVID-19: Living systematic review and network meta-analysis. BMJ 2020, 370, m2980. [CrossRef]

65. RECOVERY Collaborative Group; Horby, P.; Lim, W.S.; Emberson, J.R.; Mafham, M.; Bell, J.L.; Linsell, L.; Staplin, N.; Brightling, C.; Ustianowski, A.; et al. Dexamethasone in Hospitalized Patients with COVID-19. N. Engl. J. Med. 2021, 384, 693-704. [PubMed]

66. Angus, D.C.; Derde, L.; Al-Beidh, F.; Annane, D.; Arabi, Y.; Beane, A.; van Bentum-Puijk, W.; Berry, L.; Bhimani, Z.; Bonten, M.; et al. Effect of Hydrocortisone on Mortality and Organ Support in Patients with Severe COVID-19: The REMAP-CAP COVID-19 Corticosteroid Domain Randomized Clinical Trial. JAMA 2020, 324, 1317-1329.

67. Dequin, P.F.; Heming, N.; Meziani, F.; Plantefève, G.; Voiriot, G.; Badié, J.; François, B.; Aubron, C.; Ricard, J.D.; Ehrmann, S.; et al. Effect of Hydrocortisone on 21-Day Mortality or Respiratory Support Among Critically Ill Patients With COVID-19: A Randomized Clinical Trial. JAMA 2020, 324, 1298-1306. [CrossRef]

68. Jeronimo, C.M.P.; Farias, M.E.L.; Val, F.F.A.; Sampaio, V.S.; Alexandre, M.A.A.; Melo, G.C.; Safe, I.P.; Borba, M.G.S.; Abreu-Netto, R.L.; Maciel, A.B.S.; et al. Methylprednisolone as Adjunctive Therapy for Patients Hospitalized With COVID-19 (MetCOVID): A Randomised, Double-Blind, Phase IIb, Placebo-Controlled Trial. Clin. Infect. Dis. 2020, 72, e373-e381. [CrossRef] [PubMed]

69. Ramakrishnan, S.; Nicolau, D.V.; Langford, B.; Mahdi, M.; Jeffers, H.; Mwasuku, C.; Krassowska, K.; Fox, R.; Binnian, I.; Glover, V.; et al. Inhaled budesonide in the treatment of early COVID-19 (STOIC): A phase 2, open-label, randomised controlled trial. Lancet Respir. Med. 2021, 9, 763-772. [CrossRef]

70. Albani, F.; Fusina, F.; Granato, E.; Capotosto, C.; Ceracchi, C.; Gargaruti, R.; Santangelo, G.; Schiavone, L.; Taranto, M.S.; Tosati, C.; et al. Corticosteroid treatment has no effect on hospital mortality in COVID-19 patients. Sci. Rep. 2021, 11, 1015. [CrossRef] [PubMed]

71. Steinberg, K.P.; Hudson, L.D.; Goodman, R.B.; Hough, C.L.; Lanken, P.N.; Hyzy, R.; Thompson, B.T.; Ancukiewicz, M. National Heart, Lung, and Blood Institute Acute Respiratory Distress Syndrome (ARDS) Clinical Trials Network. Efficacy and safety of corticosteroids for persistent acute respiratory distress syndrome. N. Engl. J. Med. 2006, 354, 1671-1684. [PubMed]

72. McNally, J.D.; Leis, K.; Matheson, L.A.; Karuananyake, C.; Sankaran, K.; Rosenberg, A.M. Vitamin D deficiency in young children with severe acute lower respiratory infection. Pediatric Pulmonol. 2009, 44, 981-988. [CrossRef] 
73. Inamo, Y.; Hasegawa, M.; Saito, K.; Hayashi, R.; Ishikawa, T.; Yoshino, Y.; Hashimoto, K.; Fuchigami, T. Serum vitamin D concentrations and associated severity of acute lower respiratory tract infections in Japanese hospitalized children. Pediatrics Int. 2011, 53, 199-201. [CrossRef] [PubMed]

74. Belderbos, M.E.; Houben, M.L.; Wilbrink, B.; Lentjes, E.; Bloemen, E.M.; Kimpen, J.L.L.; Rovers, M.; Bont, L. Cord blood vitamin D deficiency is associated with respiratory syncytial virus bronchiolitis. Pediatrics 2011, 127, e1513-e1520. [CrossRef] [PubMed]

75. Teymoori-Rad, M.; Shokri, F.; Salimi, V.; Marashi, S.M. The interplay between vitamin D and viral infections. Rev. Med. Virol. 2019, 29, e2032. [CrossRef]

76. D'Avolio, A.; Avataneo, V.; Manca, A.; Cusato, J.; De Nicolò, A.; Lucchini, R.; Keller, F.; Cantù, M. 25-Hydroxyvitamin D concentrations are lower in patients with positive PCR for SARS-CoV-2. Nutrients 2020, 12, 1359. [CrossRef] [PubMed]

77. Alipio, M. Vitamin D Supplementation Could possibly Improve Clinical Outcomes of Patients Infected with Coronavirus-2019 (COVID-19). Available online: https://media-01.imu.nl/storage/energiekevrouwenacademie.nl/2851/vitamine-d-suppletie2020.pdf (accessed on 10 January 2022).

78. Karahan, S.; Katkat, F. Impact of serum $25(\mathrm{OH})$ vitamin D level on mortality in patients with COVID-19 in Turkey. J. Nutr. Health Aging 2021, 25, 189-196. [CrossRef] [PubMed]

79. Teymoori-Rad, M.; Marashi, S.M. Vitamin D and COVID-19: From potential therapeutic effects to unanswered questions. Rev. Med. Virol. 2020, 31, e2159. [CrossRef] [PubMed]

80. Wu, Y.H.; Tseng, C.P.; Cheng, M.L.; Ho, H.Y.; Shih, S.R.; Chiu, D.T. Glucose-6-phosphate dehydrogenase deficiency enhances human coronavirus 229E infection. J. Infect. Dis. 2008, 197, 812-816. [CrossRef]

81. Pfeffer, P.E.; Lu, H.; Mann, E.H.; Chen, Y.-H.; Ho, T.-R.; Cousins, D.J.; Corrigan, C.; Kelly, F.J.; Mudway, I.S.; Hawrylowicz, C.M Effects of vitamin D on inflammatory and oxidative stress responses of human bronchial epithelial cells exposed to particulate matter. PLoS ONE 2018, 13, e0200040. [CrossRef] [PubMed]

82. Teymoori-Rad, M.; Samadizadeh, S.; Tabarraei, A.; Moradi, A.; Shahbaz, M.B.; Tahamtan, A. Ten challenging questions about SARS-CoV-2 and COVID-19. Expert Rev. Respir. Med. 2020, 14, 881-888. [CrossRef]

83. Hirsch, D.; Archer, F.E.; Joshi-Kale, M.; Vetrano, A.M.; Weinberger, B. Decreased anti-inflammatory responses to vitamin D in neonatal neutrophils. Mediat. Inflamm. 2011, 2011, 598345. [CrossRef] [PubMed]

84. Baeke, F.; Takiishi, T.; Korf, H.; Gysemans, C.; Mathieu, C. Vitamin D: Modulator of the immune system. Curr. Opin. Pharmacol. 2010, 10, 482-496. [CrossRef]

85. Karkeni, E.; Morin, S.O.; Tayeh, B.B.; Goubard, A.; Josselin, E.; Castellano, R.; Fauriat, C.; Guittard, G.; Olive, D.; Nunès, J.A Vitamin D controls tumor growth and CD8+ T cell infiltration in breast cancer. Front. Immunol. 2019, 10, 1307. [CrossRef] [PubMed]

86. Rastogi, A.; Bhansali, A.; Khare, N.; Suri, V.; Yaddanapudi, N.; Sachdeva, N.; Puri, G.D.; Malhotra, P. Short term, high-dose vitamin D supplementation for COVID-19 disease: A randomised, placebo-controlled, study (SHADE study). Postgrad. Med. J. 2020, 98, 87-90. [CrossRef]

87. Annweiler, C. 9X COVID-19 survival in nursing home if had 80,000 IU dose of vitamin D in previous month-October 2020. J. Steroid Biochem. Mol. Biol. 2020. Available online: https://vitamindwiki.com/9X+COVID-19+survival+in+nursing+home+if+ had $+80 \% 2 \mathrm{C} 000+\mathrm{IU}+$ dose+of+vitamin+D+in+previous+month+\%E2\%80\%93+Oct+2020 (accessed on 10 January 2022).

88. Murai, I.H.; Fernandes, A.L.; Sales, L.P.; Pinto, A.J.; Goessler, K.F.; Duran, C.; Silva, C.; Franco, A.S.; Macedo, M.B.; Dalmolin, H.; et al. Effect of a Single High Dose of Vitamin D3 on Hospital Length of Stay in Patients with Moderate to Severe COVID-19: A Randomized Clinical Trial. JAMA 2021, 325, 1053-1060. [CrossRef] [PubMed]

89. Chakhtoura, M.; Napoli, N.; Fuleihan, G.E.H. Commentary: Myths and facts on vitamin D amidst the COVID-19 pandemic. Metabolism 2020, 109, 154276. [CrossRef] [PubMed]

90. Quesada-Gomez, J.M.; Entrenas-Castillo, M.; Bouillon, R. Vitamin D receptor stimulation to reduce acute respiratory distress syndrome (ARDS) in patients with coronavirus SARS-CoV-2 infections: Revised Ms SBMB 2020_166. J. Steroid Biochem. Mol. Biol. 2020, 202, 105719. [CrossRef] [PubMed]

91. Martineau, A.R.; Jolliffe, D.A.; Hooper, R.L.; Greenberg, L.; Aloia, J.F.; Bergman, P.; Dubnov-Raz, G.; Esposito, S.; Ganmaa, D.; Ginde, A.A.; et al. Vitamin D supplementation to prevent acute respiratory tract infections: Systematic review and meta-analysis of individual participant data. BMJ 2017, 356, i6583. [CrossRef] [PubMed]

92. Mehta, P.; McAuley, D.F.; Brown, M.; Sanchez, E.; Tattersall, R.S.; Manson, J.J. HLH Across Speciality Collaboration, UK. COVID-19: Consider cytokine storm syndromes and immunosuppression. Lancet 2020, 395, 1033-1034. [CrossRef]

93. Ruan, Q.; Yang, K.; Wang, W.; Jiang, L.; Song, J. Clinical predictors of mortality due to COVID-19 based on an analysis of data of 150 patients from Wuhan, China. Intensive Care Med. 2020, 46, 846-848. [CrossRef]

94. REMAP-CAP Investigators; Gordon, A.C.; Mouncey, P.R.; Al-Beidh, F.; Rowan, K.M.; Nichol, A.D.; Arabi, Y.M.; Annane, D.; Beane, A.; van Bentum-Puijk, W.; et al. Interleukin-6 Receptor Antagonists in Critically Ill Patients with COVID-19. N. Engl. J. Med. 2021, 384, 1491-1502. [PubMed]

95. Salama, C.; Han, J.; Yau, L.; Reiss, W.G.; Kramer, B.; Neidhart, J.D.; Criner, G.J.; Kaplan-Lewis, E.; Baden, R.; Pandit, L.; et al. Tocilizumab in Patients Hospitalized with COVID-19 Pneumonia. N. Engl. J. Med. 2021, 384, 20-30. [CrossRef] [PubMed]

96. Rosas, I.O.; Bräu, N.; Waters, M.; Go, R.C.; Hunter, B.D.; Bhagani, S.; Skiest, D.; Aziz, M.S.; Cooper, N.; Douglas, I.S.; et al. Tocilizumab in Hospitalized Patients with Severe COVID-19 Pneumonia. N. Engl. J. Med. 2021, 384, 1503-1516. [CrossRef] 
97. Stone, J.H.; Frigault, M.J.; Serling-Boyd, N.J.; Fernandes, A.D.; Harvey, L.; Foulkes, A.S.; Horick, N.K.; Healy, B.C.; Shah, R.; Bensaci, A.M.; et al. Efficacy of Tocilizumab in Patients Hospitalized with COVID-19. N. Engl. J. Med. 2020, 383, 2333-2344. [CrossRef]

98. Hermine, O.; Mariette, X.; Tharaux, P.L.; Resche-Rigon, M.; Porcher, R.; Ravaud, P. Effect of Tocilizumab vs. Usual Care in Adults Hospitalized With COVID-19 and Moderate or Severe Pneumonia: A Randomized Clinical Trial. JAMA Intern Med. 2021, 181, 32-40. [CrossRef]

99. Salvarani, C.; Dolci, G.; Massari, M.; Merlo, D.F.; Cavuto, S.; Savoldi, L.; Bruzzi, P.; Boni, F.; Braglia, L.; Turrà, C.; et al. Effect of Tocilizumab vs. Standard Care on Clinical Worsening in Patients Hospitalized with COVID-19 Pneumonia: A Randomized Clinical Trial. JAMA Intern Med. 2021, 181, 24-31. [CrossRef]

100. Bhimraj, A.; Morgan, R.L.; Shumaker, A.H.; Lavergne, V.; Baden, L.; Cheng, V.C.; Edwards, K.M.; Gandhi, R.; Gallagher, J.; Muller, W.J.; et al. Infectious Diseases Society of America Guidelines on the Treatment and Management of Patients with COVID-19. Version 4.2.0. 2021. Available online: https:/ / www.idsociety.org/practice-guideline/COVID-19-guideline-treatmentand-management/ (accessed on 24 April 2021).

101. Cavalli, G.; De Luca, G.; Campochiaro, C.; Della-Torre, E.; Ripa, M.; Canetti, D.; Oltolini, C.; Castiglioni, B.; Din, C.T.; Boffini, N.; et al. Interleukin-1 blockade with high-dose anakinra in patients with COVID-19, acute respiratory distress syndrome, and hyperinflammation: A retrospective cohort study. Lancet Rheumatol. 2020, 2, e325-e331. [CrossRef]

102. Pontali, E.; Volpi, S.; Antonucci, G.; Castellaneta, M.; Buzzi, D.; Tricerri, F.; Angelelli, A.; Caorsi, R.; Feasi, M.; Calautti, F.; et al. Safety and efficacy of early high-dose IV anakinra in severe COVID-19 lung disease. J. Allergy Clin. Immunol. 2020, 146, 213-215. [CrossRef]

103. Huet, T.; Beaussier, H.; Voisin, O.; Jouveshomme, S.; Dauriat, G.; Lazareth, I.; Sacco, E.; Naccache, J.-M.; Bézie, Y.; Laplanche, S.; et al. Anakinra for severe forms of COVID-19: A cohort study. Lancet Rheumatol. 2020, 2, e393-e400. [CrossRef]

104. Ucciferri, C.; Auricchio, A.; Di Nicola, M.; Potere, N.; Abbate, A.; Cipollone, F.; Vecchiet, J.; Falasca, K. Canakinumab in a subgroup of patients with COVID-19. Lancet Rheumatol. 2020, 2, e457-e458. [CrossRef]

105. CORIMUNO-19 Collaborative Group. Effect of anakinra versus usual care in adults in hospital with COVID-19 and mild-tomoderate pneumonia (CORIMUNO-ANA-1): A randomised controlled trial. Lancet Respir. Med. 2021, 9, 295-304. [CrossRef]

106. Somagutta, M.K.R.; Pormento, M.K.L.; Hamid, P.; Hamdan, A.; Khan, M.A.; Desir, R.; Vijayan, R.; Shirke, S.; Jeyakumar, R.; Dogar, Z.; et al. The Safety and Efficacy of Anakinra, an Interleukin-1 Antagonist in Severe Cases of COVID-19: A Systematic Review and Meta-Analysis. Infect. Chemother. 2021, 53, 221-237. [CrossRef]

107. Katze, M.G.; He, Y.; Gale, M., Jr. Viruses and interferon: A fight for supremacy. Nat. Rev. Immunol. 2002, 2, 675-687. [CrossRef]

108. Clementi, N.; Ferrarese, R.; Criscuolo, E.; Diotti, R.A.; Castelli, M.; Scagnolari, C.; Burioni, R.; Antonelli, G.; Clementi, M.; Mancini, N. Interferon- $\beta-1$ a Inhibition of Severe Acute Respiratory Syndrome-Coronavirus 2 In Vitro When Administered After Virus Infection. J. Infect. Dis. 2020, 222, 722-725. [CrossRef] [PubMed]

109. Bastard, P.; Rosen, L.B.; Zhang, Q.; Michailidis, E.; Hoffmann, H.-H.; Zhang, Y.; Dorgham, K.; Philippot, Q.; Rosain, J.; Béziat, V.; et al. Autoantibodies against type I IFNs in patients with life-threatening COVID-19. Science 2020, 370, eabd4585. [CrossRef]

110. Zhang, Q.; Bastard, P.; Liu, Z.; Le Pen, J.; Moncada-Velez, M.; Chen, J.; Ogishi, M.; Sabli, I.K.D.; Hodeib, S.; Korol, C.; et al. Inborn errors of type I IFN immunity in patients with life-threatening COVID-19. Science 2020, 370, eabd4570. [CrossRef] [PubMed]

111. Davoudi-Monfared, E.; Rahmani, H.; Khalili, H.; Hajiabdolbaghi, M.; Salehi, M.; Abbasian, L.; Kazemzadeh, H.; Yekaninejad, M.S. A Randomized Clinical Trial of the Efficacy and Safety of Interferon $\beta-1$ a in Treatment of Severe COVID-19. Antimicrob. Agents Chemother. 2020, 64, e01061-20. [CrossRef]

112. Lee, J.S.; Shin, E.-C. The type I interferon response in COVID-19: Implications for treatment. Nat. Rev. Immunol. 2020, 20, 585-586. [CrossRef] [PubMed]

113. Wang, N.; Zhan, Y.; Zhu, L.; Hou, Z.; Liu, F.; Song, P.; Qiu, F.; Wang, X.; Zou, X.; Wan, D.; et al. Retrospective Multicenter Cohort Study Shows Early Interferon Therapy Is Associated with Favorable Clinical Responses in COVID-19 Patients. Cell Host Microbe 2020, 28, 455-464.e2. [CrossRef] [PubMed]

114. Major, J.; Crotta, S.; Llorian, M.; McCabe, T.M.; Gad, H.H.; Priestnall, S.L.; Hartmann, R.; Wack, A. Type I and III interferons disrupt lung epithelial repair during recovery from viral infection. Science 2020, 369, 712-717. [CrossRef]

115. Laing, R.; Gillan, V.; Devaney, E. Ivermectin-Old Drug, New Tricks? Trends Parasitol. 2017, 33, 463-472. [CrossRef]

116. Heidary, F.; Gharebaghi, R. Ivermectin: A systematic review from antiviral effects to COVID-19 complementary regimen. J. Antibiot. 2020, 73, 593-602. [CrossRef] [PubMed]

117. Kaur, H.; Shekhar, N.; Sharma, S.; Sarma, P.; Prakash, A.; Medhi, B. Ivermectin as a potential drug for treatment of COVID-19: An in-sync review with clinical and computational attributes. Pharmacol. Rep. 2021, 73, 736-749. [CrossRef] [PubMed]

118. Rajter, J.C.; Sherman, M.S.; Fatteh, N.; Vogel, F.; Sacks, J.; Rajter, J.J. Use of Ivermectin Is Associated with Lower Mortality in Hospitalized Patients with Coronavirus Disease 2019: The Ivermectin in COVID Nineteen Study. Chest 2021, 159, 85-92. [CrossRef]

119. Shiraki, K.; Daikoku, T. Favipiravir, an anti-influenza drug against life-threatening RNA virus infections. Pharmacol. Ther. 2020, 209, 107512. [CrossRef]

120. Furuta, Y.; Komeno, T.; Nakamura, T. Favipiravir (T-705), a broad spectrum inhibitor of viral RNA polymerase. Proc. Jpn. Acad. Ser. B Phys. Biol. Sci. 2017, 93, 449-463. [CrossRef] [PubMed] 
121. A Ivashchenko, A.; A Dmitriev, K.; Vostokova, N.V.; Azarova, V.N.; A Blinow, A.; Egorova, A.N.; Gordeev, I.G.; Ilin, A.P.; Karapetian, R.N.; Kravchenko, D.V.; et al. AVIFAVIR for Treatment of Patients with Moderate COVID-19: Interim Results of a Phase II/III Multicenter Randomized Clinical Trial. Clin. Infect. Dis. 2020, 73, 531-534.

122. Cai, Q.; Yang, M.; Liu, D.; Chen, J.; Shu, D.; Xia, J.; Liao, X.; Gu, Y.; Cai, Q.; Yang, Y.; et al. Experimental Treatment with Favipiravir for COVID-19: An Open-Label Control Study. Engineering 2020, 6, 1192-1198. [CrossRef]

123. Wehbe, Z.; Wehbe, M.; Iratni, R.; Pintus, G.; Zaraket, H.; Yassine, H.M.; Eid, A.H. Repurposing Ivermectin for COVID-19: Molecular Aspects and Therapeutic Possibilities. Front. Immunol. 2021, 12, 663586. [CrossRef]

124. Agostini, M.L.; Pruijssers, A.J.; Chappell, J.D.; Gribble, J.; Lu, X.; Andres, E.L.; Bluemling, G.R.; Lockwood, M.A.; Sheahan, T.P.; Sims, A.C.; et al. Small-molecule antiviral $\beta$-d-N 4-hydroxycytidine inhibits a proofreading-intact coronavirus with a high genetic barrier to resistance. J. Virol. 2019, 93, e01348-19. [CrossRef]

125. Singh, A.K.; Singh, A.; Singh, R.; Misra, A. Molnupiravir in COVID-19: A systematic review of literature. Diabetes Metab. Syndr 2021, 15, 102329. [CrossRef]

126. Hashemian, S.M.R.; Pourhanifeh, M.H.; Hamblin, M.R.; Shahrzad, M.K.; Mirzaei, H. RdRp inhibitors and COVID-19: Is molnupiravir a good option? Biomed. Pharm. 2022, 146, 112517. [CrossRef]

127. Fischer, W.; Eron, J.J.; Holman, W.; Cohen, M.S.; Fang, L.; Szewczyk, L.J.; Sheahan, T.P.; Baric, R.; Mollan, K.R.; Wolfe, C.R.; et al. Molnupiravir, an Oral Antiviral Treatment for COVID-19. medRxiv 2021. [CrossRef]

128. Mahase, E. COVID-19: UK becomes first country to authorise antiviral molnupiravir. BMJ 2021, 375, n2697. [CrossRef]

129. Imran, M.; Arora, M.K.; Asdaq, S.M.B.; Alam Khan, S.; Alaqel, S.I.; Alshammari, M.K.; Alshehri, M.M.; Alshrari, A.S.; Ali, A.M.; Al-Shammeri, A.M.; et al. Discovery, Development, and Patent Trends on Molnupiravir: A Prospective Oral Treatment for COVID-19. Molecules 2021, 26, 5795. [CrossRef]

130. Oldfield, V.; PLosker, G.L. Lopinavir/Ritonavir. Drugs 2006, 66, 1275-1299. [CrossRef]

131. RECOVERY Collaborative Group. Lopinavir-ritonavir in patients admitted to hospital with COVID-19 (RECOVERY): A randomised, controlled, open-label, platform trial. Lancet 2020, 396, 1345-1352. [CrossRef]

132. Sadeghi, A.; Asgari, A.A.; Norouzi, A.; Kheiri, Z.; Anushirvani, A.; Montazeri, M.; Hosamirudsai, H.; Afhami, S.; Akbarpour, E.; Aliannejad, R.; et al. Sofosbuvir and daclatasvir compared with standard of care in the treatment of patients admitted to hospital with moderate or severe coronavirus infection (COVID-19): A randomized controlled trial. J. Antimicrob. Chemother. 2020, 75 , 3379-3385. [CrossRef]

133. Eslami, G.; Mousaviasl, S.; Radmanesh, E.; Jelvay, S.; Bitaraf, S.; Simmons, B.; Wentzel, H.; Hill, A.; Sadeghi, A.; Freeman, J.; et al. The impact of sofosbuvir/daclatasvir or ribavirin in patients with severe COVID-19. J. Antimicrob. Chemother. 2020, 75, 3366-3372. [CrossRef]

134. Kasgari, H.A.; Moradi, S.; Shabani, A.M.; Babamahmoodi, F.; Badabi, A.R.D.; Davoudi, L.; Alikhani, A.; Omran, A.H.; Saeedi, M.; Merat, S.; et al. Evaluation of the efficacy of sofosbuvir plus daclatasvir in combination with ribavirin for hospitalized COVID19 patients with moderate disease compared with standard care: A single-centre, randomized controlled trial. J. Antimicrob. Chemother. 2020, 75, 3373-3378. [CrossRef]

135. RECOVERY Collaborative Group. Azithromycin in patients admitted to hospital with COVID-19 (RECOVERY): A randomised, controlled, open-label, platform trial. Lancet 2021, 397, 605-612. [CrossRef]

136. Gautret, P.; Lagier, J.C.; Parola, P.; Hoang, V.T.; Meddeb, L.; Mailhe, M.; Doudier, B.; Courjon, J.; Giordanengo, V.; Vieira, V.E.; et al. Hydroxychloroquine and azithromycin as a treatment of COVID-19: Results of an open-label non-randomized clinical trial. Int. J. Antimicrob. Agents 2020, 56, 105949. [CrossRef]

137. Rosenberg, E.S.; Dufort, E.M.; Udo, T.; Wilberschied, L.A.; Kumar, J.; Tesoriero, J.; Weinberg, P.; Kirkwood, J.; Muse, A.; DeHovitz, J.; et al. Association of Treatment with Hydroxychloroquine or Azithromycin with In-Hospital Mortality in Patients With COVID-19 in New York State. JAMA 2020, 323, 2493-2502. [CrossRef]

138. Molina, J.; Delaugerre, C.; Le Goff, J.; Mela-Lima, B.; Ponscarme, D.; Goldwirt, L.; de Castro, N. No evidence of rapid antiviral clearance or clinical benefit with the combination of hydroxychloroquine and azithromycin in patients with severe COVID-19 infection. Med. Mal. Infect. 2020, 50, 384. [CrossRef]

139. Furtado, R.H.M.; Berwanger, O.; A Fonseca, H.; Corrêa, T.D.; Ferraz, L.R.; Lapa, M.G.; Zampieri, F.G.; Veiga, V.C.; Azevedo, L.C.P.; Rosa, R.G.; et al. Azithromycin in addition to standard of care versus standard of care alone in the treatment of patients admitted to the hospital with severe COVID-19 in Brazil (COALITION II): A randomised clinical trial. Lancet 2020, 396, 959-967. [CrossRef]

140. Million, M.; Lagier, J.-C.; Gautret, P.; Colson, P.; Fournier, P.-E.; Amrane, S.; Hocquart, M.; Mailhe, M.; Esteves-Vieira, V.; Doudier B.; et al. Early treatment of COVID-19 patients with hydroxychloroquine and azithromycin: A retrospective analysis of 1061 cases in Marseille, France. Travel Med. Infect. Dis. 2020, 35, 101738. [CrossRef]

141. Deftereos, S.G.; Giannopoulos, G.; Vrachatis, D.A.; Siasos, G.D.; Giotaki, S.G.; Gargalianos, P.; Metallidis, S.; Sianos, G.; Baltagiannis, S.; Panagopoulos, P.; et al. Effect of Colchicine vs Standard Care on Cardiac and Inflammatory Biomarkers and Clinical Outcomes in Patients Hospitalized with Coronavirus Disease 2019: The GRECCO-19 Randomized Clinical Trial. JAMA Netw. Open 2020, 3, e2013136. [CrossRef]

142. RECOVERY Trial Closes Recruitment to Colchicine Treatment for Patients Hospitalised with COVID-19. Available online: https:/ / www.recoverytrial.net/news/recovery-trial-closes-recruitment-to-colchicine-treatment-for-patients-hospitalisedwith-COVID-19 (accessed on 26 April 2021). 
143. Vrachatis, D.A.; Giannopoulos, G.V.; Giotaki, S.G.; Raisakis, K.; Kossyvakis, C.; Iliodromitis, K.E.; Reimers, B.; Tousoulis, D.; Cleman, M.; Stefanadis, C.; et al. Impact of colchicine on mortality in patients with COVID-19: A meta-analysis. Hell. J. Cardiol. 2021, 62, 374-377. [CrossRef]

144. Lenze, E.J.; Mattar, C.; Zorumski, C.F.; Stevens, A.; Schweiger, J.; Nicol, G.E.; Miller, J.P.; Yang, L.; Yingling, M.; Avidan, M.S.; et al. Fluvoxamine vs Placebo and Clinical Deterioration in Outpatients with Symptomatic COVID-19: A Randomized Clinical Trial. JAMA 2020, 324, 2292-2300. [CrossRef] [PubMed]

145. Seftel, D.; Boulware, D.R. Prospective Cohort of Fluvoxamine for Early Treatment of Coronavirus Disease 19. Open Forum Infect. Dis. 2021, 8, ofab050. [CrossRef]

146. Calusic, M.; Marcec, R.; Luksa, L.; Jurkovic, I.; Kovac, N.; Mihaljevic, S.; Likic, R. Safety and efficacy of fluvoxamine in COVID-19 ICU patients: An open label, prospective cohort trial with matched controls. Br. J. Clin. Pharm. 2021. [CrossRef]

147. Mehra, M.R.; Desai, S.S.; Kuy, S.; Henry, T.D.; Patel, A.N. Cardiovascular Disease, Drug Therapy, and Mortality in COVID-19. N. Engl. J. Med. 2020, 382, e102. [CrossRef]

148. Minotti, C.; Tirelli, F.; Barbieri, E.; Giaquinto, C.; Donà, D. How is immunosuppressive status affecting children and adults in SARS-CoV-2 infection? A systematic review. J. Infect. 2020, 81, e61-e66. [CrossRef]

149. Tepasse, P.R.; Hafezi, W.; Lutz, M.; Kühn, J.; Wilms, C.; Wiewrodt, R.; Sackarnd, J.; Keller, M.; Schmidt, H.H.; Vollenberg, R. Persisting SARS-CoV-2 viraemia after rituximab therapy: Two cases with fatal outcome and a review of the literature. Br. J. Haematol. 2020, 190, 185-188. [CrossRef]

150. Clark, E.; Guilpain, P.; Filip, I.L.; Pansu, N.; Le Bihan, C.; Cartron, G.; Tchernonog, E.; Roubille, C.; Morquin, D.; Makinson, A.; et al. Convalescent plasma for persisting COVID-19 following therapeutic lymphocyte depletion: A report of rapid recovery. Br. J. Haematol. 2020, 190, e154-e156. [CrossRef]

151. Salazar, E.; Christensen, P.A.; Graviss, E.A.; Nguyen, D.T.; Castillo, B.; Chen, J.; Lopez, B.V.; Eagar, T.N.; Yi, X.; Zhao, P.; et al. Treatment of Coronavirus Disease 2019 Patients with Convalescent Plasma Reveals a Signal of Significantly Decreased Mortality. Am. J. Pathol. 2020, 190, 2290-2303. [CrossRef] [PubMed]

152. Liu, S.T.H.; Lin, H.-M.; Baine, I.; Wajnberg, A.; Gumprecht, J.P.; Rahman, F.; Rodriguez, D.; Tandon, P.; Bassily-Marcus, A.; Bander, J.; et al. Convalescent plasma treatment of severe COVID-19: A propensity score-matched control study. Nat. Med. 2020, 26, 1708-1713. [CrossRef]

153. Xia, X.; Li, K.; Wu, L.; Wang, Z.; Zhu, M.; Huang, B.; Li, J.; Wang, Z.; Wu, W.; Wu, M.; et al. Improved clinical symptoms and mortality among patients with severe or critical COVID-19 after convalescent plasma transfusion. Blood 2020, 136, 755-759. [CrossRef] [PubMed]

154. Libster, R.; Marc, G.P.; Wappner, D.; Coviello, S.; Bianchi, A.; Braem, V.; Esteban, I.; Caballero, M.T.; Wood, C.; Berrueta, M.; et al. Early High-Titer Plasma Therapy to Prevent Severe COVID-19 in Older Adults. N. Engl. J. Med. 2021, 384, 610-618. [CrossRef] [PubMed]

155. Piechotta, V.; Chai, K.L.; Valk, S.J.; Doree, C.; Monsef, I.; Wood, E.M.; Lamikanra, A.; Kimber, C.; McQuilten, Z.; So-Osman, C.; et al. Convalescent plasma or hyperimmune immunoglobulin for people with COVID-19: A living systematic review. Cochrane Database Syst. Rev. 2020, 7, Cd013600.

156. Li, L.; Zhang, W.; Hu, Y.; Tong, X.; Zheng, S.; Yang, J.; Kong, Y.; Ren, L.; Wei, Q.; Mei, H.; et al. Effect of Convalescent Plasma Therapy on Time to Clinical Improvement in Patients with Severe and Life-threatening COVID-19: A Randomized Clinical Trial. JAMA 2020, 324, 460-470. [CrossRef] [PubMed]

157. Agarwal, A.; Mukherjee, A.; Kumar, G.; Chatterjee, P.; Bhatnagar, T.; Malhotra, P. Convalescent plasma in the management of moderate COVID-19 in adults in India: Open label phase II multicentre randomised controlled trial (PLACID Trial). BMJ 2020, 371, m3939. [CrossRef] [PubMed]

158. Simonovich, V.A.; Pratx, L.D.B.; Scibona, P.; Beruto, M.V.; Vallone, M.G.; Vázquez, C.; Savoy, N.; Giunta, D.H.; Pérez, L.G.; Sánchez, M.D.L.; et al. A Randomized Trial of Convalescent Plasma in COVID-19 Severe Pneumonia. N. Engl. J. Med. 2021, 384, 619-629. [CrossRef]

159. FDA. In Brief: FDA Updates Emergency Use Authorization for COVID-19 Convalescent Plasma to Reflect New Data. 2021. Available online: https:/ / www.fda.gov/news-events/fda-brief/fda-brief-fda-updates-emergency-use-authorization-COVID19-convalescent-plasma-reflect-new-data (accessed on 26 April 2021).

160. De Oliveira, F.A.; Nucci, M.P.; Rego, G.N.D.A.; Alves, A.D.H.; Marti, L.C.; Nucci, L.P.; Mamani, J.B.; Gamarra, L.F. Convalescent plasma therapy in COVID-19 critically ill patients during advanced phases of clinical trials and their preliminary results. Einstein 2021, 19, eRW6186. [CrossRef]

161. Zhou, P.; Yang, X.-L.; Wang, X.-G.; Hu, B.; Zhang, L.; Zhang, W.; Si, H.-R.; Zhu, Y.; Li, B.; Huang, C.-L.; et al. A pneumonia outbreak associated with a new coronavirus of probable bat origin. Nature 2020, 579, 270-273. [CrossRef]

162. Yoshimoto, F.K. The Proteins of Severe Acute Respiratory Syndrome Coronavirus-2 (SARS CoV-2 or n-COV19), the Cause of COVID-19. Protein J. 2020, 39, 198-216. [CrossRef] [PubMed]

163. Du, L.; Yang, Y.; Zhou, Y.; Lu, L.; Li, F.; Jiang, S. MERS-CoV spike protein: A key target for antivirals. Expert Opin. Targets 2017, 21, 131-143. [CrossRef]

164. Du, L.; He, Y.; Zhou, Y.; Liu, S.; Zheng, B.J.; Jiang, S. The spike protein of SARS-CoV-A target for vaccine and therapeutic development. Nat. Rev. Microbiol. 2009, 7, 226-236. [CrossRef] 
165. Zhou, Y.; Yang, Y.; Huang, J.; Jiang, S.; Du, L. Advances in MERS-CoV Vaccines and Therapeutics Based on the Receptor-Binding Domain. Viruses 2019, 11, 60. [CrossRef]

166. Jiang, S.; Du, L.; Shi, Z. An emerging coronavirus causing pneumonia outbreak in Wuhan, China: Calling for developing therapeutic and prophylactic strategies. Emerg. Microbes. Infect. 2020, 9, 275-277. [CrossRef]

167. Baum, A.; Ajithdoss, D.; Copin, R.; Zhou, A.; Lanza, K.; Negron, N.; Ni, M.; Wei, Y.; Mohammadi, K.; Musser, B.; et al. REGNCOV2 antibodies prevent and treat SARS-CoV-2 infection in rhesus macaques and hamsters. Science 2020, 370, 1110-1115. [CrossRef]

168. Baum, A.; Fulton, B.O.; Wloga, E.; Copin, R.; Pascal, K.E.; Russo, V.; Giordano, S.; Lanza, K.; Negron, N.; Ni, M.; et al. Antibody cocktail to SARS-CoV-2 spike protein prevents rapid mutational escape seen with individual antibodies. Science 2020, 369, 1014-1018. [CrossRef]

169. Rogers, T.F.; Zhao, F.; Huang, D.; Beutler, N.; Burns, A.; He, W.T.; Limbo, O.; Smith, C.; Song, G.; Woehl, J.; et al. Isolation of potent SARS-CoV-2 neutralizing antibodies and protection from disease in a small animal model. Science 2020, 369, 956-963. [CrossRef]

170. Zost, S.J.; Gilchuk, P.; Case, J.B.; Binshtein, E.; Chen, R.E.; Nkolola, J.P.; Schäfer, A.; Reidy, J.X.; Trivette, A.; Nargi, R.S.; et al. Potently neutralizing and protective human antibodies against SARS-CoV-2. Nature 2020, 584, 443-449. [CrossRef]

171. Robbiani, D.F.; Gaebler, C.; Muecksch, F.; Lorenzi, J.; Wang, Z.; Cho, A.; Agudelo, M.; Barnes, C.O.; Gazumyan, A.; Finkin, S.; et al. Convergent antibody responses to SARS-CoV-2 in convalescent individuals. Nature 2020, 584, 437-442. [CrossRef]

172. Hansen, J.; Baum, A.; Pascal, K.E.; Russo, V.; Giordano, S.; Wloga, E.; Fulton, B.O.; Yan, Y.; Koon, K.; Patel, K.; et al. Studies in humanized mice and convalescent humans yield a SARS-CoV-2 antibody cocktail. Science 2020, 369, 1010-1014. [CrossRef]

173. A Study of LY3819253 (LY-CoV555) and LY3832479 (LY-CoV016) in Preventing SARS-CoV-2 Infection and COVID-19 in Nursing Home Residents and Staff (BLAZE-2). 2020. Available online: https:/ / clinicaltrials.gov/ct2/show / NCT04497987 (accessed on 27 April 2021).

174. Clinical Trials of Monoclonal Antibodies to Prevent COVID-19 Now Enrolling. 2020. Available online: https:/ /www.nih.gov/ news-events/news-releases/clinical-trials-monoclonal-antibodies-prevent-COVID-19-now-enrolling (accessed on 27 April 2021).

175. Chen, P.; Nirula, A.; Heller, B.; Gottlieb, R.L.; Boscia, J.; Morris, J.; Huhn, G.; Cardona, J.; Mocherla, B.; Stosor, V.; et al. SARS-CoV-2 Neutralizing Antibody LY-CoV555 in Outpatients with COVID-19. N. Engl. J. Med. 2021, 384, 229-237. [CrossRef] [PubMed]

176. Casirivimab and Imdevimab EUA Letter of Authorization. 2020. Available online: https://www.fda.gov/media/143891 /download (accessed on 27 April 2021).

177. Bamlanivimab and Etesevimab EUA Letter of Authorization. 2021. Available online: https://www.fda.gov/media/145801 /download (accessed on 27 April 2021).

178. IDSA. Monoclonal Antibodies, Guidelines. 2021. Available online: https:/ / www.idsociety.org/COVID-19-real-time-learningnetwork/therapeutics-and-interventions/monoclonal-antibodies/ (accessed on 27 April 2021).

179. Gottlieb, R.L.; Nirula, A.; Chen, P.; Boscia, J.; Heller, B.; Morris, J.; Huhn, G.; Cardona, J.; Mocherla, B.; Stosor, V.; et al. Effect of Bamlanivimab as Monotherapy or in Combination with Etesevimab on Viral Load in Patients with Mild to Moderate COVID-19: A Randomized Clinical Trial. JAMA 2021, 325, 632-644. [CrossRef] [PubMed]

180. The COVID-19 Treatment Guidelines Panel's Statement on the Emergency Use Authorization of Anti-SARS-CoV-2 Monoclonal Antibodies for the Treatment of COVID-19. 2021. Available online: https:/ /www.COVID19treatmentguidelines.nih.gov/antisars-cov-2-antibody-products/anti-sars-cov-2-monoclonal-antibodies/ (accessed on 28 April 2021).

181. Anti-SARS-CoV-2 Monoclonal Antibodies: Selected Clinical Data. 2021. Available online: https://www.COVID1 9treatmentguidelines.nih.gov/tables/table-3a/ (accessed on 27 April 2021).

182. ACTIV-3/TICO Bamlanivimab Study Group; Lundgren, J.D.; Grund, B.; Barkauskas, C.E.; Holland, T.L.; Gottlieb, R.L.; Sandkovsky, U.; Brown, S.M.; Knowlton, K.U.; Self, W.H.; et al. A Neutralizing Monoclonal Antibody for Hospitalized Patients with COVID-19. N. Engl. J. Med. 2021, 384, 905-914. [PubMed]

183. Wolf, J.; Abzug, M.J.; Wattier, R.L.; Sue, P.K.; Vora, S.B.; Zachariah, P.; Dulek, D.E.; Waghmare, A.; Olivero, R.; Downes, K.J.; et al. Initial Guidance on Use of Monoclonal Antibody Therapy for Treatment of Coronavirus Disease 2019 in Children and Adolescents. J. Pediatric Infect. Dis. Soc. 2021, 10, 629-634. [CrossRef] [PubMed]

184. Locht, C. Vaccines against COVID-19. Anaesth. Crit. Care Pain Med. 2020, 39, 703-705. [CrossRef]

185. WHO. Coronavirus (COVID-19) Dashboard. 2021. Available online: https:/ COVID19.who.int/ (accessed on 28 April 2021).

186. Raina, S.K.; Kumar, R. "Covishield and Covaxin"-India's contribution to global COVID-19 pandemic. J. Fam. Med. Prim. Care 2021, 10, 2433-2435. [CrossRef]

187. Tukhvatulin, A.I.; Dolzhikova, I.V.; Shcheblyakov, D.V.; Zubkova, O.V.; Dzharullaeva, A.S.; Kovyrshina, A.V.; Lubenets, N.L.; Grousova, D.M.; Erokhova, A.S.; Botikov, A.G.; et al. An open, non-randomised, phase 1/2 trial on the safety, tolerability, and immunogenicity of single-dose vaccine "Sputnik Light" for prevention of coronavirus infection in healthy adults. Lancet Reg. Health Eur. 2021, 11, 100241. [CrossRef]

188. Aguilar-Guerra, T.L.; Fajardo-Díaz, E.M.; Gorry, C. Cuba's National Regulatory Authority \& COVID-19: Olga Lidia JacoboCasanueva MS Director, Center for State Control of Medicines and Medical Devices (CECMED). MEDICC Rev. 2021, $23,9-14$.

189. Hassine, I.H. COVID-19 vaccines and variants of concern: A review. Rev. Med. Virol. 2021, e2313. [CrossRef] 
190. Yang, S.; Li, Y.; Dai, L.; Wang, J.; He, P.; Li, C.; Fang, X.; Wang, C.; Zhao, X.; Huang, E.; et al. Safety and immunogenicity of a recombinant tandem-repeat dimeric RBD-based protein subunit vaccine (ZF2001) against COVID-19 in adults: Two randomised, double-blind, placebo-controlled, phase 1 and 2 trials. Lancet Infect. Dis 2021, 21, 1107-1119. [CrossRef]

191. Wang, Y.; Yang, C.; Song, Y.; Coleman, J.R.; Stawowczyk, M.; Tafrova, J.; Tasker, S.; Boltz, D.; Baker, R.; Garcia, L.; et al. Scalable live-attenuated SARS-CoV-2 vaccine candidate demonstrates preclinical safety and efficacy. Proc. Natl. Acad. Sci. USA 2021, 118, e2102775118. [CrossRef] [PubMed]

192. Abdoli, A.; Aalizadeh, R.; Aminianfar, H.; Kianmehr, Z.; Teimoori, A.; Azimi, E.; Emamipour, N.; Eghtedardoost, M.; Siavashi, V.; Jamshidi, H.; et al. Safety and potency of BIV1-CovIran inactivated vaccine candidate for SARS-CoV-2: A preclinical study. Rev. Med. Virol. 2021, e2305. [CrossRef] [PubMed]

193. Dong, C.; Liang, Q.; Ji, T.; Gu, J.; Feng, J.; Shuai, M.; Zhang, X.; Zhao, R.; Gu, Z. Determinants of Vaccine Acceptance against COVID-19 in China: Perspectives on Knowledge and DrVac-COVID19S Scale. Int. J. Environ. Res. Public Health 2021, $18,11192$. [CrossRef] [PubMed]

194. Lien, C.E.; Kuo, T.Y.; Lin, Y.J.; Lian, W.C.; Lin, M.Y.; Liu, L.T.; Cheng, J.; Chou, Y.C.; Chen, C. Evaluating the Neutralizing Ability of a CpG-Adjuvanted S-2P Subunit Vaccine Against Severe Acute Respiratory Syndrome Coronavirus 2 (SARS-CoV-2) Variants of Concern. Clin. Infect. Dis. 2021, ciab711. [CrossRef] [PubMed]

195. Dey, A.; Rajanathan, T.C.; Chandra, H.; Pericherla, H.P.; Kumar, S.; Choonia, H.S.; Bajpai, M.; Singh, A.K.; Sinha, A.; Saini, G.; et al. Immunogenic potential of DNA vaccine candidate, ZyCoV-D against SARS-CoV-2 in animal models. Vaccine, Vaccine 2021, 39, 4108-4116. [CrossRef] [PubMed]

196. Li, L.; Honda-Okubo, Y.; Huang, Y.; Jang, H.; Carlock, M.A.; Baldwin, J.; Piplani, S.; Bebin-Blackwell, A.G.; Forgacs, D.; Sakamoto, K.; et al. Immunisation of ferrets and mice with recombinant SARS-CoV-2 spike protein formulated with Advax-SM adjuvant protects against COVID-19 infection. Vaccine 2021, 39, 5940-5953. [CrossRef] [PubMed]

197. Zhu, F.-C.; Li, Y.-H.; Guan, X.-H.; Hou, L.-H.; Wang, W.-J.; Li, J.-X.; Wu, S.-P.; Wang, B.-S.; Wang, Z.; Wang, L.; et al. Safety, tolerability, and immunogenicity of a recombinant adenovirus type-5 vectored COVID-19 vaccine: A dose-escalation, open-label, non-randomised, first-in-human trial. Lancet 2020, 395, 1845-1854. [CrossRef]

198. Zhu, F.-C.; Guan, X.-H.; Li, Y.-H.; Huang, J.-Y.; Jiang, T.; Hou, L.-H.; Li, J.-X.; Yang, B.-F.; Wang, L.; Wang, W.-J.; et al. Immunogenicity and safety of a recombinant adenovirus type-5-vectored COVID-19 vaccine in healthy adults aged 18 years or older: A randomised, double-blind, placebo-controlled, phase 2 trial. Lancet 2020, 396, 479-488. [CrossRef]

199. Voysey, M.; Clemens, S.; Madhi, S.A.; Weckx, L.Y.; Folegatti, P.M.; Aley, P.K.; Angus, B.; Baillie, V.L.; Barnabas, S.L.; Bhorat, Q.E.; et al. Safety and efficacy of the ChAdOx1 nCoV-19 vaccine (AZD1222) against SARS-CoV-2: An interim analysis of four randomised controlled trials in Brazil, South Africa, and the UK. Lancet 2021, 397, 99-111. [CrossRef]

200. Putter, J.S. Immunotherapy for COVID-19: Evolving treatment of viral infection and associated adverse immunological reactions. Transfus. Apher. Sci. 2021, 60, 103093. [CrossRef]

201. Ewer, K.J.; Barrett, J.R.; Belij-Rammerstorfer, S.; Sharpe, H.; Makinson, R.; Morter, R.; Flaxman, A.; Wright, D.; Bellamy, D.; Bittaye, M.; et al. T cell and antibody responses induced by a single dose of ChAdOx1 nCoV-19 (AZD1222) vaccine in a phase $1 / 2$ clinical trial. Nat. Med. 2021, 27, 270-278. [CrossRef] [PubMed]

202. Ramasamy, M.N.; Minassian, A.M.; Ewer, K.J.; Flaxman, A.L.; Folegatti, P.M.; Owens, D.R.; Voysey, M.; Aley, P.K.; Angus, B.; Babbage, G.; et al. Safety and immunogenicity of ChAdOx1 nCoV-19 vaccine administered in a prime-boost regimen in young and old adults (COV002): A single-blind, randomised, controlled, phase 2/3 trial. Lancet 2020, 396, 1979-1993. [CrossRef]

203. Walsh, E. RNA-based COVID-19 vaccine BNT162b2 selected for a pivotal efficacy study. medRxiv 2020, $10,20176651$.

204. Jackson, L.A.; Anderson, E.J.; Rouphael, N.G.; Roberts, P.C.; Makhene, M.; Coler, R.N.; McCullough, M.P.; Chappell, J.D.; Denison, M.R.; Stevens, L.J.; et al. An mRNA vaccine against SARS-CoV-2-Preliminary report. N. Engl. J. Med. 2020, 383, $1920-1931$. [CrossRef] [PubMed]

205. BioNtech Web. mRNA-Vaccines. 2021. Available online: https://biontech.de/COVID-19-portal/mrna-vaccines (accessed on 9 January 2021).

206. CD Bioparticles. Lipid Nanoparticle Formulation and Development for mRNA Vaccine Delivery. 2021. Available online: https: / / www.cd-bioparticles.net/lipid-nanoparticle-formulation-and-development-for-mrna-vaccine-delivery? msclkid=fc6 633f009f111b8592c6c07b45384 (accessed on 9 January 2021).

207. Anderson, P.O. Maternal Vaccination and Breastfeeding. Breastfeed. Med. 2019, 14, 215-217. [CrossRef] [PubMed]

208. COVID-19 vaccines. In Drugs and Lactation Database (LactMed); National Library of Medicine: Bethesda, MD, USA, 2006.

209. World Health Organization. MODULE 2-Types of Vaccine and Adverse Reactions. 2021. Available online: https://vaccinesafety-training.org/overview-and-outcomes-2.html (accessed on 9 January 2022).

210. Padmanabhan, R.; Abed, H.S.; Meskin, N.; Khattab, T.; Shraim, M.; Al-Hitmi, M.A. A review of mathematical model-based scenario analysis and interventions for COVID-19. Comput. Methods Programs Biomed. 2021, 209, 106301. [CrossRef]

211. Sadique, M.Z.; Adams, E.J.; Edmunds, W.J. Estimating the costs of school closure for mitigating an influenza pandemic. BMC Public Health 2008, 8, 135. [CrossRef]

212. Du, S.Q.; Yuan, W. Mathematical modeling of interaction between innate and adaptive immune responses in COVID-19 and implications for viral pathogenesis. J. Med. Virol. 2020, 92, 1615-1628. [CrossRef]

213. Tang, L.; Zhou, Y.; Wang, L.; Purkayastha, S.; Zhang, L.; He, J.; Wang, F.; Song, P.X. A Review of Multi-Compartment Infectious Disease Models. Int. Stat. Rev. 2020, 88, 462-513. [CrossRef] 
214. Fang, F.C.; A Benson, C.; del Rio, C.; Edwards, K.M.; Fowler, V.G.; Fredricks, D.N.; Limaye, A.P.; E Murray, B.; Naggie, S.; Pappas, P.G.; et al. COVID-19-Lessons Learned and Questions Remaining. Clin. Infect. Dis. 2021, 72, 2225-2240. [CrossRef]

215. World Health Organization. Mental Health and COVID-19. 2020. Available online: https://www.euro.who.int/en/health-topics/ health-emergencies/coronavirus-COVID-19/publications-and-technical-guidance/mental-health-and-COVID-19 (accessed on 9 January 2022).

216. Loiwal, M. 20\% increase in patients with mental illness since coronavirus outbreak: Survey. India Today 2020, 31. Available online: https:/ / www.indiatoday.in/india/story/20-per-cent-increase-in-patients-with-mental-illness-since-coronavirusoutbreak-survey-1661584-2020-03-31 (accessed on 10 January 2022).

217. Foley, N.C.; Affoo, R.H.; Martin, R.E. A systematic review and meta-analysis examining pneumonia-associated mortality in dementia. Dement. Geriatr. Cogn. Disord. 2015, 39, 52-67. [CrossRef]

218. Bauer, K.; Schwarzkopf, L.; Graessel, E.; Holle, R. A claims data-based comparison of comorbidity in individuals with and without dementia. BMC Geriatr. 2014, 14, 1-13. [CrossRef]

219. Yamamoto, V.; Bolanos, J.F.; Fiallos, J.; Strand, S.E.; Morris, K.; Shahrokhinia, S.; Cushing, T.R.; Hopp, L.; Tiwari, A.; Hariri, R.; et al. COVID-19: Review of a 21st Century Pandemic from Etiology to Neuro-psychiatric Implications. J. Alzheimer's Dis. 2020, 77, 459-504. [CrossRef]

220. Scarpa, R.; Costa, L.; Del Puente, A.; Caso, F. Role of thymopoiesis and inflamm-aging in COVID-19 phenotype. Pediatr. Neonatol. 2020, 61, 364-365. [CrossRef]

221. Brown, E.E.; Kumar, S.; Rajji, T.K.; Pollock, B.G.; Mulsant, B.H. Anticipating and Mitigating the Impact of the COVID-19 Pandemic on Alzheimer's Disease and Related Dementias. Am. J. Geriatr. Psychiatry 2020, 28, 712-721. [CrossRef]

222. Kubota, T.; Kuroda, N. Exacerbation of neurological symptoms and COVID-19 severity in patients with preexisting neurological disorders and COVID-19: A systematic review. Clin. Neurol. Neurosurg. 2021, 200, 106349. [CrossRef]

223. Lanza, G.; Godani, M.; Ferri, R.; Raggi, A. Impact of COVID-19 pandemic on the neuropsychiatric status of Wilson's disease. World J. Gastroenterol. 2021, 27, 6733-6736. [CrossRef]

224. Coronavirus (COVID-19) Vaccinations-Statistics and Research. 2021. Available online: https://ourworldindata.org/COVIDvaccinations (accessed on 29 April 2021).

225. Rapid Increase of a SARS-CoV-2 Variant with Multiple Spike Protein Mutations Observed in the United Kingdom. 2020. Available online: https:/ / www.ecdc.europa.eu/sites/default/files/documents/SARS-CoV-2-variant-multiple-spike-protein-mutationsUnited-Kingdom.pdf (accessed on 29 April 2021).

226. Volz, E.; Mishra, S.; Chand, M.; Barrett, J.C.; Johnson, R.; Geidelberg, L.; Hinsley, W.R.; Laydon, D.J.; Dabrera, G.; O’Toole, Á.; et al. Transmission of SARS-CoV-2 Lineage, B.1.1.7 in England: Insights from linking epidemiological and genetic data. medRxiv 2021, 12, 20249034.

227. Davies, N.G.; Abbott, S.; Barnard, R.C.; Jarvis, C.I.; Kucharski, A.J.; Munday, J.D.; Pearson, C.A.B.; Russell, T.W.; Tully, D.C.; Washburne, A.D.; et al. Estimated transmissibility and impact of SARS-CoV-2 lineage B.1.1.7 in England. Science 2021, 372, eabg3055. [CrossRef]

228. Investigation of Novel SARS-CoV-2 Variant: Variant of Concern 202012/01. Technical Briefing 5. 2021. Available online: https://assets.publishing.service.gov.uk/government/uploads/system/uploads/attachment_data/file/959426/Variant_of_ Concern_VOC_202012_01_Technical_Briefing_5.pdf (accessed on 29 April 2021).

229. Challen, R.; Brooks-Pollock, E.; Read, J.M.; Dyson, L.; Tsaneva-Atanasova, K.; Danon, L. Risk of mortality in patients infected with SARS-CoV-2 variant of concern 202012/1: Matched cohort study. BMJ 2021, 372, n579. [CrossRef]

230. Frampton, D.; Rampling, T.; Cross, A.; Bailey, H.; Heaney, J.; Byott, M.; Scott, R.; Sconza, R.; Price, J.; Margaritis, M.; et al. Genomic characteristics and clinical effect of the emergent SARS-CoV-2 B.1.1.7 lineage in London, UK: A whole-genome sequencing and hospital-based cohort study. Lancet Infect. Dis. 2021, 21, 1246-1256. [CrossRef]

231. Muik, A.; Wallisch, A.K.; Sänger, B.; Swanson, K.A.; Mühl, J.; Chen, W.; Cai, H.; Maurus, D.; Sarkar, R.; Türeci, Ö.; et al. Neutralization of SARS-CoV-2 lineage B.1.1.7 pseudovirus by BNT162b2 vaccine-elicited human sera. Science 2021, 371, $1152-1153$. [CrossRef]

232. Wu, K.; Werner, A.P.; Koch, M.; Choi, A.; Narayanan, E.; Stewart-Jones, G.B.E.; Colpitts, T.; Bennett, H.; Boyoglu-Barnum, S.; Shi, W.; et al. Serum Neutralizing Activity Elicited by mRNA-1273 Vaccine-Preliminary Report. N. Engl. J. Med. 2021, 384, 1468-1470. [CrossRef]

233. Shen, X.; Tang, H.; Pajon, R.; Smith, G.; Glenn, G.M.; Shi, W.; Korber, B.; Montefiori, D.C. Neutralization of SARS-CoV-2 Variants, B.1.429 and B.1.351. N. Engl. J. Med. 2021, 384, 2352-2354. [CrossRef]

234. Emary, K.R.; Golubchik, T.; Aley, P.K.; Ariani, C.V.; Angus, B.; Bibi, S.; Blane, B.; Bonsall, D.; Cicconi, P.; Charlton, S.; et al. Efficacy of ChAdOx1 nCoV-19 (AZD1222) vaccine against SARS-CoV-2 variant of concern 202012/01 (B.1.1.7): An exploratory analysis of a randomised controlled trial. Lancet 2021, 397, 1351-1362. [CrossRef]

235. Wang, G.L.; Wang, Z.Y.; Duan, L.J.; Meng, Q.C.; Jiang, M.D.; Cao, J.; Yao, L.; Zhu, K.L.; Cao, W.C.; Ma, M.J. Susceptibility of Circulating SARS-CoV-2 Variants to Neutralization. N. Engl. J. Med. 2021, 384, 2354-2356. [CrossRef]

236. Tegally, H.; Wilkinson, E.; Giovanetti, M.; Iranzadeh, A.; Fonseca, V.; Giandhari, J.; Doolabh, D.; Pillay, S.; San, E.J.; Msomi, N.; et al. Detection of a SARS-CoV-2 variant of concern in South Africa. Nature 2021, 592, 438-443. [CrossRef] 
237. Wibmer, C.K.; Ayres, F.; Hermanus, T.; Madzivhandila, M.; Kgagudi, P.; Oosthuysen, B.; Lambson, B.E.; de Oliveira, T.; Vermeulen, M.; van der Berg, K.; et al. SARS-CoV-2 501Y.V2 escapes neutralization by South African COVID-19 donor plasma. Nat. Med. 2021, 27, 622-625. [CrossRef]

238. Xie, X.; Liu, Y.; Liu, J.; Zhang, X.; Zou, J.; Fontes-Garfias, C.R.; Xia, H.; Swanson, K.A.; Cutler, M.; Cooper, D.; et al. Neutralization of SARS-CoV-2 spike 69/70 deletion, E484K and N501Y variants by BNT162b2 vaccine-elicited sera. Nat. Med. 2021, 27, 620-621. [CrossRef]

239. Liu, Y.; Liu, J.; Xia, H.; Zhang, X.; Fontes-Garfias, C.R.; Swanson, K.A.; Cai, H.; Sarkar, R.; Chen, W.; Cutler, M.; et al. Neutralizing Activity of BNT162b2-Elicited Serum-Preliminary Report. N. Engl. J. Med. 2021, 384, 1466-1468. [CrossRef] [PubMed]

240. Zhou, D.; Dejnirattisai, W.; Supasa, P.; Liu, C.; Mentzer, A.J.; Ginn, H.M.; Zhao, Y.; Duyvesteyn, H.M.E.; Tuekprakhon, A.; Nutalai, R.; et al. Evidence of escape of SARS-CoV-2 variant B.1.351 from natural and vaccine-induced sera. Cell 2021, 184, $2348-2361$. [CrossRef] [PubMed]

241. Madhi, S.A.; Baillie, V.; Cutland, C.L.; Voysey, M.; Koen, A.L.; Fairlie, L.; Padayachee, S.D.; Dheda, K.; Barnabas, S.L.; Bhorat, Q.E.; et al. Efficacy of the ChAdOx1 nCoV-19 COVID-19 Vaccine against the B.1.351 Variant. N. Engl. J. Med. 2021, 384, 1885-1898. [CrossRef]

242. Lamarca, A.P.; de Almeida, L.G.P.; Francisco, R.D.S., Jr.; Lima, L.F.A.; Scortecci, K.C.; Perez, V.P.; Brustolini, O.J.; Sousa, E.S.S.; Secco, D.A.; Santos, A.M.G.; et al. Genomic surveillance of SARS-CoV-2 tracks early interstate transmission of P.1 lineage and diversification within P.2 clade in Brazil. PLoS Negl. Trop. Dis. 2021, 15, e0009835. [CrossRef]

243. Wang, P.; Casner, R.G.; Nair, M.S.; Wang, M.; Yu, J.; Cerutti, G.; Liu, L.; Kwong, P.D.; Huang, Y.; Shapiro, L.; et al. Increased resistance of SARS-CoV-2 variant P.1 to antibody neutralization. Cell Host Microbe. 2021, 29, 747-751.e4. [CrossRef]

244. Sabino, E.C.; Buss, L.F.; Carvalho, M.P.S.; Prete, C.A., Jr.; Crispim, M.A.E.; Fraiji, N.A.; Pereira, R.H.M.; Parag, K.V.; da Silva Peixoto, P.; Kraemer, M.U.G.; et al. Resurgence of COVID-19 in Manaus, Brazil, despite high seroprevalence. Lancet 2021, 397, 452-455. [CrossRef]

245. Fabiani, M.; Margiotti, K.; Viola, A.; Mesoraca, A.; Giorlandino, C. Mild Symptomatic SARS-CoV-2 P.1 (B.1.1.28) Infection in a Fully Vaccinated 83-Year-Old Man. Pathogens 2021, 10, 614. [CrossRef]

246. Clemens, S.A.C.; Folegatti, P.M.; Emary, K.R.W.; Weckx, L.Y.; Ratcliff, J.; Bibi, S.; De Almeida Mendes, A.V.; Milan, E.P.; Pittella, A.; Schwarzbold, A.V.; et al. Efficacy of ChAdOx1 nCoV-19 (AZD1222) vaccine against SARS-CoV-2 lineages circulating in Brazil. Nat. Commun. 2021, 12, 5861. [CrossRef]

247. Aleem, A.; Akbar Samad, A.B.; Slenker, A.K. Emerging Variants of SARS-CoV-2 And Novel Therapeutics Against Coronavirus (COVID-19). In StatPearls; StatPearls Publishing: Treasure Island, FL, USA, 2021.

248. Davis, C.; Logan, N.; Tyson, G.; Orton, R.; Harvey, W.T.; Perkins, J.S.; Mollett, G.; Blacow, R.M.; Peacock, T.P.; Barclay, W.S.; et al. Reduced neutralisation of the Delta (B.1.617.2) SARS-CoV-2 variant of concern following vaccination. PLoS Pathog. 2021, 17, e1010022. [CrossRef]

249. Lopez Bernal, J.; Andrews, N.; Gower, C.; Gallagher, E.; Simmons, R.; Thelwall, S.; Stowe, J.; Tessier, E.; Groves, N.; Dabrera, G.; et al. Effectiveness of COVID-19 Vaccines against the B.1.617.2 (Delta) Variant. N. Engl. J. Med. 2021, 385, 585-594. [CrossRef]

250. World Health Organization. Classification of Omicron (B.1.1.529): SARS-CoV-2 Variant of Concern. 2021. Available online: https:/ / www.who.int/news/item/26--11--2021-classification-of-omicron--(b.1.1.529)-sars-cov-2-variant-of-concern (accessed on 2 December 2021).

251. Melissa Healy. Did Failure to Adequately Treat HIV Patients Give Rise to the Omicron Variant? 2021. Los Angeles Times. Available online: https:/ /www.latimes.com/science/story/2021-12-02/did-omicron-coronavirus-variant-arise-in-patient-withuncontrolled-hiv (accessed on 2 December 2021).

252. Gao, S.J.; Guo, H.; Luo, G. Omicron variant (B.1.1.529) of SARS-CoV-2, a global urgent public health alert. J. Med. Virol. 2021, 94, 1255-1256. [CrossRef] [PubMed]

253. Chen, J.; Wang, R.; Gilby, N.B.; Wei, G.W. Omicron (B.1.1.529): Infectivity, vaccine breakthrough, and antibody resistance. J. Chem. Inf. Model. 2022, 62, 412-422. [CrossRef] [PubMed]

254. Dawood, A.A. Increasing the frequency of omicron variant mutations boosts the immune response and may reduce the virus virulence. Microb. Pathog. 2022, 164, 105400. [CrossRef] [PubMed]

255. Garrett, N.; Tapley, A.; Andriesen, J.; Seocharan, I.; Fisher, L.H.; Bunts, L.; Espy, N.; Wallis, C.L.; Randhawa, A.K.; Ketter, N. High Rate of Asymptomatic Carriage Associated with Variant Strain Omicron. medRxiv 2022. [CrossRef]

256. Dyer, O. COVID-19: Omicron is causing more infections but fewer hospital admissions than delta, South African data show. BMJ 2021, 375, n3104. [CrossRef]

257. Mahase, E. COVID-19: Hospital admission 50-70\% less likely with omicron than delta, but transmission a major concern. BMJ 2021, 375, n3151. [CrossRef]

258. Liu, J.; Chandrashekar, A.; Sellers, D.; Barrett, J.; Lifton, M.; McMahan, K.; Sciacca, M.; VanWyk, H.; Wu, C.; Yu, J.; et al. Vaccines Elicit Highly Cross-Reactive Cellular Immunity to the SARS-CoV-2 Omicron Variant. medRxiv 2022. [CrossRef]

259. Syed, A.M.; Ciling, A.; Khalid, M.M.; Sreekumar, B.; Chen, P.Y.; Kumar, G.R.; Silva, I.; Milbes, B.; Kojima, N.; Hess, V.; et al. Omicron mutations enhance infectivity and reduce antibody neutralization of SARS-CoV-2 virus-like particles. medRxiv 2022. [CrossRef]

260. Singhal, T. The Emergence of Omicron: Challenging Times Are Here Again! Indian J. Pediatr. 2022. [CrossRef] 
261. Neil Ferguson, A.G.; Hinsley, W.; Volz, E. On Behalf of the Imperial College COVID-19 Response and Team. Report 50: Hospitalisation Risk for Omicron Cases in England; Imperial College: London, UK, 2021; Available online: https://www.imperial.ac.uk/mrcglobal-infectious-disease-analysis/COVID-19/report-50-severity-omicron/ (accessed on 29 April 2021).

262. Hoffmann, M.; Krüger, N.; Schulz, S.; Cossmann, A.; Rocha, C.; Kempf, A.; Nehlmeier, I.; Graichen, L.; Moldenhauer, A.S.; Winkler, M.S.; et al. The Omicron variant is highly resistant against antibody-mediated neutralization: Implications for control of the COVID-19 pandemic. Cell 2021, 3, 447-456. [CrossRef]

263. Accorsi, E.K.; Britton, A.; Fleming-Dutra, K.E.; Smith, Z.R.; Shang, N.; Derado, G.; Miller, J.; Schrag, S.J.; Verani, J.R. Association Between 3 Doses of mRNA COVID-19 Vaccine and Symptomatic Infection Caused by the SARS-CoV-2 Omicron and Delta Variants. JAMA 2022, 327, 639-651. [CrossRef] [PubMed]

264. Garcia-Beltran, W.F.; Denis, K.J.S.; Hoelzemer, A.; Lam, E.C.; Nitido, A.D.; Sheehan, M.L.; Berrios, C.; Ofoman, O.; Chang, C.C.; Hauser, B.M.; et al. mRNA-based COVID-19 vaccine boosters induce neutralizing immunity against SARS-CoV-2 Omicron variant. Cell 2022, 3, 447-456. [CrossRef] [PubMed]

265. Costa Clemens, S.A.; Weckx, L.; Clemens, R.; Almeida Mendes, A.V.; Ramos Souza, A.; Silveira, M.B.V.; da Guarda, S.N.F.; de Nobrega, M.M.; de Moraes Pinto, M.I.; Gonzalez, I.G.S.; et al. Heterologous versus homologous COVID-19 booster vaccination in previous recipients of two doses of CoronaVac COVID-19 vaccine in Brazil (RHH-001): A phase 4, non-inferiority, single blind, randomised study. Lancet 2022, 399, 521-529. [CrossRef]

266. Pérez-Then, E.; Lucas, C.; Monteiro, V.S.; Miric, M.; Brache, V.; Cochon, L.; Vogels, C.B.F.; Malik, A.A.; De la Cruz, E.; Jorge, A.; et al. Neutralizing antibodies against the SARS-CoV-2 Delta and Omicron variants following heterologous CoronaVac plus BNT162b2 booster vaccination. Nat. Med. 2022. [CrossRef]

267. Munro, A.P.S.; Janani, L.; Cornelius, V.; Aley, P.K.; Babbage, G.; Baxter, D.; Bula, M.; Cathie, K.; Chatterjee, K.; Dodd, K.; et al. Safety and immunogenicity of seven COVID-19 vaccines as a third dose (booster) following two doses of ChAdOx1 nCov-19 or BNT162b2 in the UK (COV-BOOST): A blinded, multicentre, randomised, controlled, phase 2 trial. Lancet 2021, 398, 2258-2276. [CrossRef] 